Review

\title{
About Northrop Grumman
}

\author{
${ }^{1}$ Relly Victoria Petrescu, ${ }^{2}$ Raffaella Aversa, ${ }^{3}$ Bilal Akash, ${ }^{4}$ Juan Corchado, ${ }^{2}$ Antonio Apicella and \\ ${ }^{1}$ Florian Ion Tiberiu Petrescu
}

${ }^{1}$ ARoTMM-IFToMM, Bucharest Polytechnic University, Bucharest, (CE), Romania

${ }^{2}$ Advanced Material Lab, Department of Architecture and Industrial Design,

Second University of Naples, 81031 Aversa (CE), Italy

${ }^{3}$ Dean of School of Graduate Studies and Research, American University of Ras Al Khaimah, UAE

${ }^{4}$ University of Salamanca, Spain

Article history

Received: 09-07-2017

Revised: 10-07-2017

Accepted: 18-08-2017

Corresponding Author: Florian Ion Tiberiu Petrescu ARoTMM-IFToMM, Bucharest Polytechnic University, Bucharest, (CE), Romania E-mail: scipub02@gmail.com
Abstract: The Northrop Grumman (formerly Ryan Aeronautical) RQ-4 Global Hawk (known as Tier II+ during development) is an Unmanned Aerial Vehicle (UAV) used by the United States Air Force and Navy and the German Air Force as a surveillance aircraft. The Northrop Grumman B2 Spirit (also known as the Stealth Bomber) is an American strategic bomber, featuring low observable stealth technology designed for penetrating dense anti-aircraft defenses; it is able to deploy both conventional and nuclear weapons. The bomber has a crew of two and can drop up to eighty $500 \mathrm{lb}(230 \mathrm{~kg})$-class JDAM GPS-guided bombs, or sixteen 2,400 lb $(1,100 \mathrm{~kg})$ B83 nuclear bombs. The B-2 is the only aircraft that can carry large airto-surface standoff weapons in a stealth configuration. The BQM-74 Chukar is a series of aerial target drones produced by Northrop. The Chukar has gone through three major revisions, including the initial MQM-74A Chukar I, the MQM-74C Chukar II and the BQM-74C Chukar III. They are recoverable, remote controlled, subsonic aerial target, capable of speeds up to Mach 0.86 and altitudes from 30 to $40,000 \mathrm{ft}$ (10 to $12,000 \mathrm{~m}$ ). Northrop Grumman Corporation (NYSE: NOC) is an American global aerospace and defense technology company formed by the 1994 purchase of Grumman by Northrop. The company was the fourth-largest defense contractor in the world as of 2010 and the largest builder of naval vessels. Northrop Grumman employs over 75,000 people worldwide. Its 2010 annual revenue is reported at US\$34 billion. Northrop Grumman ranks \#72 on the 2011 Fortune 500 list of America's largest corporations and ranks in the top ten military-friendly employers. It has its headquarters in Falls Church, Virginia. Separate sectors, such as Aerospace Systems, produce aircraft for the US and other nations. The B-2 Spirit strategic bomber, the E-8C Joint STARS surveillance aircraft, the RQ-4 Global Hawk and the T-38 Talon supersonic trainer, are used by the US Air Force. The US Army uses Northrop Grumman's RQ-5 Hunter unmanned air vehicle, which has been in operational use for more than 10 years. The US Navy uses Northrop Grumman-built aerial vehicles such as the BQM-74 Chukar, RQ-4 Global Hawk based BAMS UAS, C-2 Greyhound, E-2 Hawkeye and the EA-6B Prowler. Northrop Grumman provides major components and assemblies for different aircraft such as F/A-18 Hornet, F/A18E/F Super Hornet and the EA-18G Growler. Many aircraft, such as the F-5, T-38 Talon and E-2 Hawkeye are used by other nations.

Keywords: Northrop Grumman, Aerospace, Spacecraft Propulsion, US Army, Jet Engines, Spirit Strategic Bomber, Defense Contractor 


\section{Introduction}

Northwest Grumman (formerly Ryan Aeronautical) RQ-4 Global Hawk (known as Tier II + during development) is an Unmanned Aerial Vehicle (UAV) used by the US Navy and US Navy and German Air Force Surveillance (Petrescu and Petrescu, 2009; 2011; 2012a; 2012b; 2013a; 2013b; 2013c).

Northrop Grumman B-2 (also known as the Stealth Bomber) is a strategic American bomber with low observable stealth technology designed to penetrate dense air defense; it is capable of implementing both conventional and nuclear weapons. The bomb has a twoperson team and can drop up to eighty JDAM bombs (230 kg) or sixteen 1200-pound B200 nuclear bombs. B2 is the only aircraft that can carry large surface protection weapons in a stealth configuration.

BQM-74 Chukar is a series of aircraft targeted by the Northrop plane. Chukar has gone through three major revisions, including Chukar I MQM-74A, Chukar II MQM-74C and Chukar III BQM-74C. They can capture remote subsonic air, capable of accelerating up to 0.86 Mach and at altitudes from 10 to $12,000 \mathrm{~m}$.

Northrop Grumman Corporation (NYSE: NOC) is a global aviation and defense technology company formed by the acquisition of Grumman in 1994 by Northrop. The company was the fourth largest defense contractor in the world since 2010 and the largest shipbuilder. Northrop Grumman employs more than 75,000 people worldwide. Annual revenue for 2010 is reported at \$ 34 billion. Northrop Grumman is ranked 72th in 2011 on the list of the largest corporations in America and ranked third among the top ten military (Headquartered in Falls Church, Virginia).

Separate sectors, such as aerospace systems, produce aircraft for the United States and other nations. The B-2, E-8C Common STARS, the Global Hawk RH-4 crew and the T-38 Talon supersonic instructor are used by the US Air Force. The US Army uses a RQ-5 Hunter aircraft carrier from Northrop Grumman, which has been used for over 10 years. The US ship uses Northrop Grummanbuilt aerial vehicles, such as BQM-74 Chukar, RQ-4 Global Hawk based on BAMS UAS, C-2 Greyhound, E2 Hawkeye and EA-6B Prowler. Northrop Grumman provides major components and assemblies for various aircraft such as F/A-18 Hornet, F/A-18E/F Super Hornet and EA-18G Growler. Many aircraft, such as F-5, T-38 Talon and E-2 Hawkeye, are used by other nations (Petrescu and Petrescu, 2013b).

\section{Methods and Materials}

\section{Northrop Grumman Global Hawk}

The Northrop Grumman (formerly Ryan Aeronautical; Fig. 1) RQ-4 Global Hawk (known as Tier II + during development) is an Unmanned Aerial Vehicle
(UAV) used by the United States Air Force and Navy and the German Air Force as a surveillance aircraft.

In respect of the role of design and functionality, Global Hawk is very similar to the model in 1950, Lockheed U-2. He is the one who can snapshot mode to inform the active commander about the theater of war or in order to offer such an overall view and a systematic surveillance target. For this purpose, Global Hawk is able to provide radar images with the Summary of the high Resolution (SAR) - that can penetrate the cloud cover and through the storm of sand - thanks to the images Electro-Optical/Infrared (EO/IR) areas. He can investigate daily up to 40,000 square kilometers of land, without a stop in a qualitatively superior.

The plane is used as a platform for high altitude for surveillance and security. The tasks conferred upon him Global Hawk covers the spectrum of the capacity for the collection of information in order to support the forces in military operations in the world. According to the Air Force, capabilities of the aircraft allow steering more accurate weapons and a better protection of the forces through the superior capabilities of the supervisory board. Practically all the fire is directed to the perfect and on time, due to the information collected and retransmitted snapshot of Global hawk.

A Global Hawk costs about 35 million USD, but if we take into account the expenses for the scientific research they were doppelgangers required and the development of his final costs on the appliance shall amount to 218 million dollars (Petrescu and Petrescu, 2013b).

The first seven aircraft have been constructed on the basis of the program Advanced Concept Technology Demonstration Mode (ACTD), sponsored by DARPA, with the purpose of the design and the capabilities of its operational. Because of the circumstances of the world of that period (with many military conflicts opened and theaters of battle actual), the capacities of the aircraft were even from the start very solicitated, so that even the aircraft prototype have been sent to operate for the Air Force US to the war in Afghanistan (normally the samples had to be made in a quiet place).

By a movement of unusual, aircraft already entered in the initial production (with a low rate), while were still in the engineering and testing. They have been produced nine new aircraft in category 10 (sometimes called configurations RQ-4A), of which the first two (Fig. 2) have been sold to the American, two other have been sent to Iraq to support the operations from there. The last plane Block 10 (in this batch initial) has been delivered on 26 June 2006.

In the desire to improve the ability of the aircraft, aircraft body has been redesigned with the wings and with the section of the nose rebuilt. The amendments made to the (with the name of the RQ-4B Block 20), allow the aircraft to carry up to 3 tons of cargo useful. These changes have been entered at the first aircraft from the second batch, Block 20, the 17th Global production 
Hawk, which was launched in the framework of a ceremony on 25 August 2006. The first flight of the Block 20 on the factory USAF 42 of Palmdale, California, to the Edwards Air Force Base, took place on 1 March 2007. Testing for the development of the Block 20 took place in 2008. Future blocks of 30 and 40 aircraft, similar in size and shape with the 20, have they been scheduled for their development from 2008 until 2010. When was designed the Global Product Hawk, it has entered and a plan for its sales for more than 5 countries, including the USA and Germany.

The United States took over two of the Block 10 aircraft to assess maritime surveillance capabilities, called N-1 (BuNo 166509) and N-2 (BuNo 166510). The initial example was tested in a naval airframe configuration at Edwards for several months, then transported to the Patuxent NAS on 28 March 2006 to begin the Global Hawk Maritime Demonstration (GHMD) program. The Navy squadron VX-20 was tasked with operating the GHMD system.

The GHMD aircraft flew in RIMPAC for the first time in July 2006. Although RIMPAC operations were in the vicinity of Hawaii, the plane was operated from Edwards, requiring flights of approximately $4,000 \mathrm{~km}$ each to the operating area. Four flights were conducted, resulting in over $24 \mathrm{~h}$ of persistent maritime surveillance, coordinated with USS Abraham Lincoln and USS Bonhomme Richard. As part of the demonstration program, Global Hawk was tasked with maintaining maritime awareness, tracking contacts and supporting images for various exercise activities. The images obtained by Global Hawk were sent to the Patuxent River NAS to be processed before being transmitted to Hawaii fleet operations, thus exerting the global nature of operations on this plane.

Northrop Grumman entered a version of the RQ-4B in the US Maritime Surveillance Maritime (BAMS) UAV contract. On April 22, 2008, the announcement was made that Northrop Grumman RQ-4N had won the offer on Tuesday, awarding a contract worth \$1.16 billion. In September 2010, the RQ-4N was officially designated the MQ-4C.

On June 11, 2012, a US navigator RQ-4A Global Hawk collapsed near Salisbury, Maryland, during a training flight at Patuxent River Naval Air Station.

The exaggeration of program development costs led to the cancellation of the Global Hawk system. Unit costs in mid-2006 were $25 \%$ higher than initial estimates, caused both by the need to correct design weaknesses and by increasing system capabilities.

This has caused some concerns about a possible cessation of the program if its benefits in terms of national security could not be justified. However, in June 2006, Global Hawk was restructured. Completion of an Air Force operational assessment report was postponed from August 2005 to November 2007 due to manufacturing delays and delays.

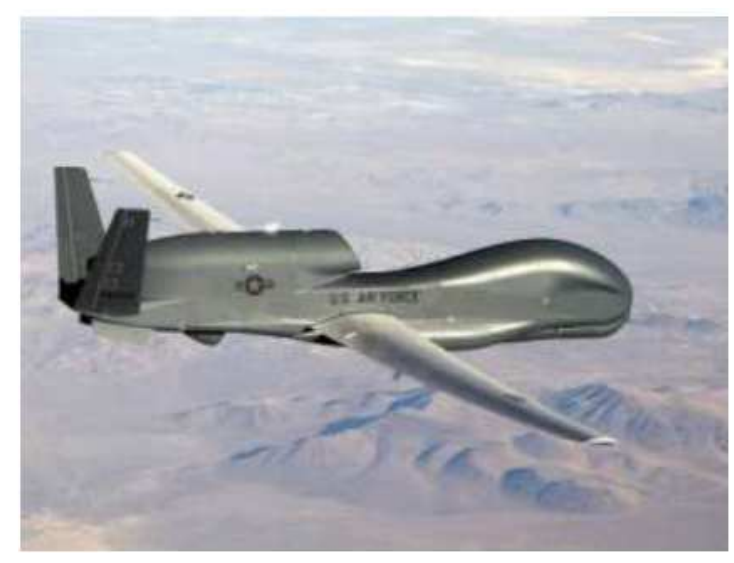

Fig. 1. Northrop Grumman RQ-4 Global Hawk Source: (Petrescu and Petrescu, 2013b)

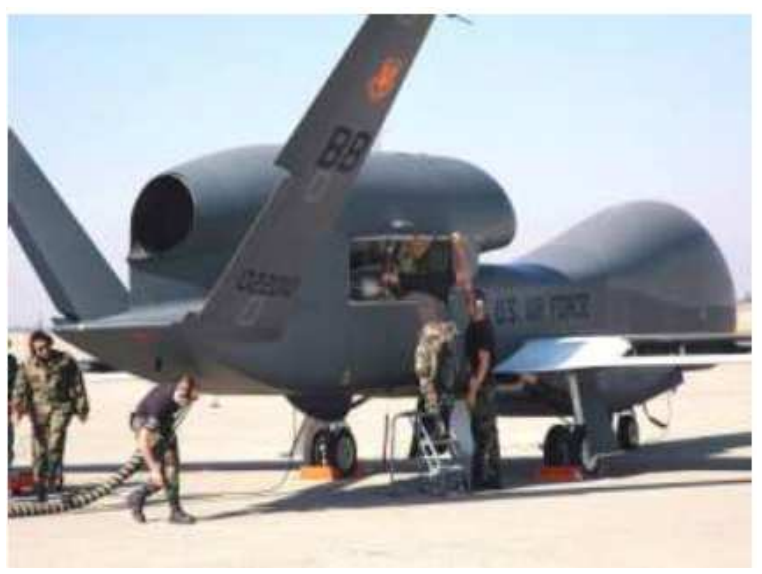

Fig. 2. A maintenance crew prepares a global hawk for a test at Beale air force base. Source: (Petrescu and Petrescu, 2013b)

The operational assessment report was launched in March 2007 and the production of the 54 planned air vehicles was extended by two years by 2015 . In February 2011, the Air Force reduced the planned acquisition of RQ-4 Block 40 aircraft from 22 to 11 in a cost-cutting move.

The US Department of Defense, Test and Operational Assessment (DOT \& E) found that the RQ-4B "is not operationally effective" for its mission due to aircraft reliability issues in June 2011.

In June 2011, Global Hawk was certified by the Secretary of Defense as being critical to national security following the Nunn-McCurdy breach. The secretary said: "Global Hawk is essential to national security, there are no alternatives to Global Hawk that offer acceptable capabilities at a lower cost, Global Hawk costs \$220 million less per year than U-2 to operate on a U-2 can't carry the same sensors as Global Hawk and if funding is to be reduced, Global Hawk has a higher priority than other programs." 
On January 26, 2012, the Pentagon announced plans to complete the acquisition of Global Hawk Block 30 as block 30 proved to be more expensive than U-2 and the sensor suite was not as capable as the crewed plane. Also, plans have been announced to increase the acquisition of Block 40.

\section{Design}

The RQ-4 is powered by an Allison Rolls-Royce AE3007H turbocharged engine with a pressure of 7,050 lbf $(31.4 \mathrm{kN})$ and has a payload of 900 kilograms. The main fuselage is the standard, semi-monocoque aluminum construction, while the wings are made of light and high-strength composite materials.

\section{Integrated System}

The Global Hawk UAV system comprises a segment of aerial vehicles consisting of aerial vehicles with sensor loadings, avionics and data links; A ground segment consisting of a Launch and Recovery Element (LRE) and a Mission Control Element (MCE) with embedded communication equipment; A support element; And the trained staff.

The Integrated Sensor Sensor (ISS) is supplied by Raytheon and consists of a Synthetic Radar Sensor (SAR), EO and Infrared (IR) sensors. Either EO or IR sensors can work simultaneously with SAR.

Each of the sensors provides wide area search images and high-resolution spot mode.

SAR has a Ground Motion Targeting Mode (GMTI) that can provide a text message that provides the position and speed of the moving target. Both SAR and EO/IR images are processed aboard the aircraft and transmitted to the MCE as individual frames.

MCE can mosaic these frames in images before further dissemination.

Navigation is via inertial navigation with integrated global positioning updates.

Global Hawk is designed to operate autonomously and "untethered" using a satellite data connection $(\mathrm{Ku}$ or UHF) to send aircraft sensor data to the MCE.

The common data line can also be used for direct downlinking of images when UAVs operate in line view of users with compatible terrestrial stations.

The ground segment consists of a Mission Control Element (MCE) and a Lite Release and Recovery (LRE) feature provided by Raytheon.

The MCE is used for mission planning, command and control and image processing and dissemination; an LRE for controlling launch and recovery; and associated ground support equipment. (The LRE provides precision differential global positioning system corrections for navigational accuracy during takeoff and landings, while precision coded GPS supplemented with an inertial navigation system is used during mission execution.) By having separable elements in the ground segment, the MCE and the LRE can operate in geographically separate locations and the MCE can be deployed with the supported command's primary exploitation site. Both ground segments are contained in military shelters with external antennas for line-of-sight and satellite communications with the air vehicles.

\section{Sensor Packages}

The Global Hawk carries the Hughes Integrated Surveillance \& Reconnaissance (HISAR) sensor system.

HISAR is a lower-cost derivative of the ASARS-2 package that Hughes developed for the Lockheed U-2.

HISAR is also fitted in the US Army's RC-7B Airborne Reconnaissance Low-Multifunction (ARLM) manned surveillance aircraft and is being sold on the international market.

HISAR integrates an SAR-MTI system, along with an optical and an infrared imager. All three sensors are controlled and their outputs filtered by a common processor. The digital sensor data can be transmitted at up to $50 \mathrm{Mbit} / \mathrm{s}$ to a ground station in real time, either directly or through a communications satellite link.

The SAR-MTI system operates in the X-band and provides a number of operational modes.

The wide-area MTI mode can detect moving targets within a radius of 62 miles $(100 \mathrm{~km})$.

The combined SAR-MTI strip mode provides 20 foot $(6 \mathrm{~m})$ resolution over a swath 23 miles $(37 \mathrm{~km})$ wide at ranges from 12.4 to 68 miles (20 to $110 \mathrm{~km}$ ).

The SAR spot mode can provide 6 foot $(1.8 \mathrm{~m})$ resolution over 3.8 square miles (10 square $\mathrm{km}$ ), as well as provide a sea-surveillance function.

The visible and infrared images share the same gimballed sensor package and use common optics, providing a telescopic close-up capability.

It can be optionally fitted with an auxiliary SIGINT package. To improve survivability, the Global Hawk is fitted with a Raytheon developed AN/ALR-89 selfprotection suite consisting of the AN/AVR-3 Laser Warning System, AN/APR-49 Radar Warning Receiver and a jamming system. An ALE-50 towed decoy also aids in the Global Hawk's deception of enemy air defenses.

In July 2006, the US Air Force began testing segments of the improved Global Hawk Block 30 upgrades in the Benefield Anechoic Facility at Edwards AFB.

This version incorporates an extremely sensitive SIGINT processor known as the Advanced Signals Intelligence Payload.

In September 2006, testing began on a new specialty radar system, the Multi-Platform Radar Technology Insertion Program, or MP-RTIP, on board the Scaled Composites Proteus. Once validated, one Global Hawk will be modified to carry this radar set. Previously, the Air Force was considering a larger variant of the MPRTIP (known as the Wide-Area Surveillance or WAS sensor) for the canceled E-10 MC2A testbed or E8 Joint STARS aircraft (Petresc and Petrescu, 2009; 2011; 2012; 2013a 2013b; 2013c). 
In August 2010, Northrop announced that a new version, Block 40, was about to commence production; it would have new sensor capabilities, including MP-RTIP radar, emphasizing surveillance over reconnaissance.

The Block 40 design also has a modified undercarriage.

\section{Operational History}

Air Force Global Hawk flight test evaluations are performed by the 452nd Flight Test Squadron at Edwards AFB. Operational USAF aircraft are flown by the 9th Reconnaissance Wing, 12th Reconnaissance Squadron at Beale Air Force Base.

Global Hawk ATCD prototypes have been used in the War in Afghanistan and in the Iraq War.

Since April 2010, they fly the Northern Route, from Beale AFB over Canada to South-East Asia and back, reducing flight time and improving maintenance. While their data-collection capabilities have been praised, the program did lose three prototype aircraft, more than onequarter of the aircraft used in the wars, being lost.

The crashes were reported to be due to "technical failures or poor maintenance", with a failure rate per hour flown over 100 times higher than the F-16 fighters flown in the same wars.

The manufacturer stated that it was unfair to compare the failure rates of a mature design to that of a prototype aircraft.

Three Global Hawks have been lost in accidents through 2003.

On 11 February 2010 the Global Hawks deployed in the Central Command AOR accrued, 30,000 combat hours and 1,500 plus sorties.

Initial operational capability was declared for the RQ-4 Block 30 in August 2011.

After the 2011 Tōhoku earthquake and tsunami, the aircraft flew $300 \mathrm{~h}$ over the affected areas in Japan. There were also plans to survey the No. 4 reactor at the Fukushima Daiichi Nuclear Power Plant.

On 21 March 2001, aircraft number 982003, the third ACTD aircraft produced, set an official world endurance record for UAVs, at $30 \mathrm{~h}, 24 \mathrm{~min}$ and $1 \mathrm{sec}$, flying from Edwards. During the same flight, it set an absolute altitude record of $19,928 \mathrm{~m}(65,381 \mathrm{ft})$, which was later broken by the NASA Helios Prototype (although the absolute record was broken, the Global Hawk's record still stands in its FAI class category).

On 24 April 2001, a Global Hawk flew non-stop from Edwards in the US to RAAF Base Edinburgh in Australia, making history by being the first pilotless aircraft to cross the Pacific Ocean. The flight took $22 \mathrm{~h}$ and set a world record for absolute distance flown by a $\mathrm{UAV}, 13,219.86 \mathrm{~km}(8,214.44 \mathrm{mi})$.

\section{$N A S A$}

In December 2007, two Global Hawks were transferred from the U.S. Air Force to NASA's Dryden Flight Research Center at Edwards Air Force Base.
Initial research activities beginning in the second quarter of 2009 supported NASA's high-altitude, longduration Earth science missions.

The three Global Hawks were the first, sixth and seventh aircraft built under the original DARPA Advanced Concept Technology Demonstration program and were made available to NASA when the Air Force had no further need for them.

Northrop Grumman is an operational partner with NASA and will use the aircraft to demonstrate new technologies and to develop new markets for the aircraft, including possible civilian uses.

Global Hawk aircraft belonging to NASA were in use for testing purposes as of October 2009, with science missions expected to start in March 2010 (Fig. 3).

Initial science applications included measurements of the ozone layer and cross-Pacific transport of air pollutants and aerosols.

The author of the Scientific American piece speculates that the aircraft could be used for Antarctic exploration while based in and operated from Chile.

In August and September 2010 one of the two Global Hawks was loaned for NASA's GRIP Mission (Genesis and Rapid Intensification Program), with its long-term on station capabilities and long range it was the best aircraft for the mission to monitor the development of Atlantic Basin Hurricanes (Fig. 4) (Petresc and Petrescu, 2009; 2011; 2012; 2013a; 2013b; 2013c).

It was modified to equip weather sensors including $\mathrm{Ku}-$ Band Radar, Lightning sensors and Dropsondes.

It successfully flew into Hurricane Earl off the United States East Coast on September 2.

NASA's Dryden Flight Research Center operates two developmental-model Northrop Grumman Global Hawk unmanned aircraft for high-altitude, long-duration Earth science missions. Acquired from the U.S. Air Force, these autonomously flown aircraft are the first and sixth built under the original global hawk advanced concept technology demonstrator development program sponsored by the defense advanced research projects agency.

The ability of the Global Hawk to autonomously fly long distances, remain aloft for extended periods of time and carry large payloads brings a new capability to the science community for measuring, monitoring and observing remote locations of Earth not feasible or practical with piloted aircraft, most other robotic or remotely operated aircraft, or space satellites.

The aircraft's 11,000-nautical-mile range and $32 \mathrm{~h}$ endurance, together with satellite and line-of-site communication links to the ground control station, allow for eventual worldwide operation. Dedicated satellite communication links provide researchers with direct access to their onboard instrument packages during missions. Researchers have the ability to monitor instrument function from the ground control station and evaluate selected data in real time. 


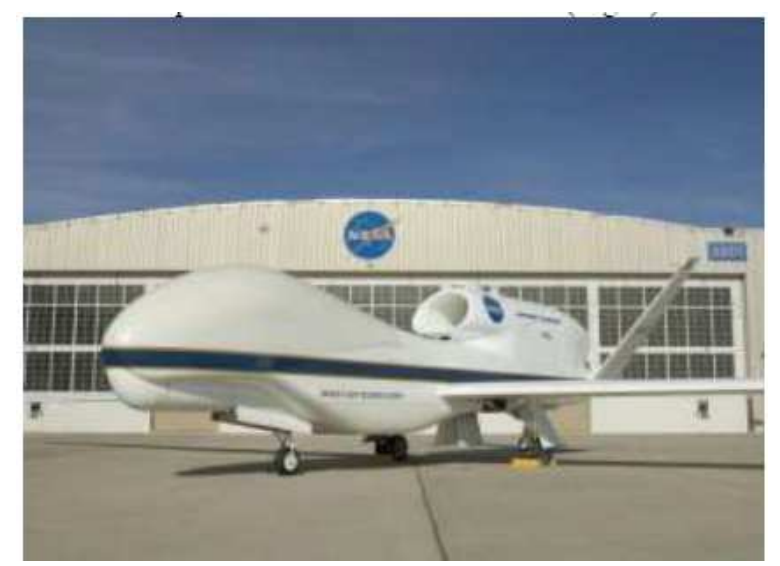

Fig. 3. A global hawk at NASA's Dryden flight research center. Source: (Petrescu and Petrescu, 2013b)

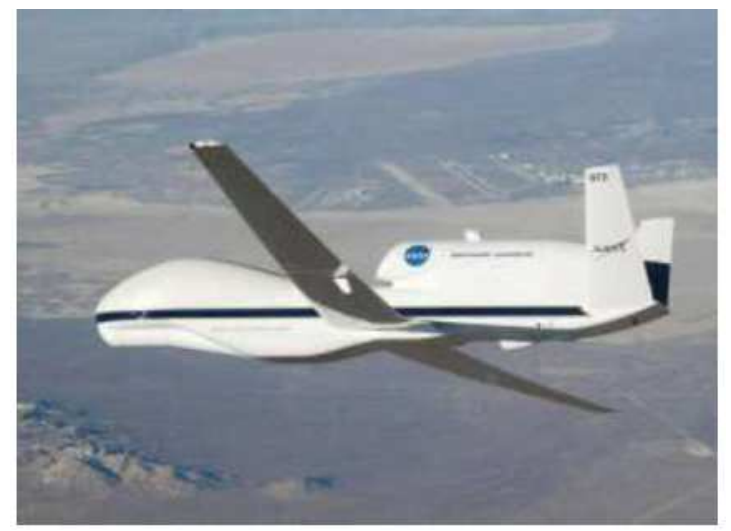

Fig. 4. A NASA global hawk in flight. Source: (Petrescu and Petrescu, 2013b)

Northrop Grumman Aerospace Systems, Rancho Bernardo, Calif. and NASA Dryden created a partnership to operate Global Hawk missions from Dryden. NASA and Northrop Grumman share use of the ground control station, maintenance facilities and the NASA Global Hawk aircraft.

NASA's Science Mission Directorate supports NASA research activities on the aircraft. The science mission directorate has teamed with the National oceanic and atmospheric administration and the department of energy to investigate unmanned aircraft systems, specifically the global Hawk, for earth observation research.

Initial operational capability for Global Hawk science missions from NASA Dryden was achieved in 2010. A portable ground control station is now operational, making deployments and missions possible worldwide. The hurricane and severe storm sentinel multi-year study beginning in 2012 will be the first deployment opportunity for two NASA Global Hawks that will operate temporarily from NASA's wallops flight facility in wallops Island, Va.
The 44-foot-long Global Hawk has a wingspan of more than 116 feet, a height of 15 feet and a gross takeoff weight of 26,750 pounds, including a 1,500-pound payload capability. A single Rolls-Royce AE3007H turbofan engine powers the aircraft. The distinctive V-tail, engine cover, aft fuselage and wings are constructed primarily of graphite composite materials. The center fuselage is constructed of conventional aluminum, while various fairings and radomes feature fiberglass composite construction.

NASA has an additional Advanced Technology Demonstrator, the seventh Global Hawk built and two Block 10 aircraft transferred from the U.S. Air Force. These aircraft are being used to provide parts for the flying Global Hawks and could be used for future missions (Fig. 5).

NASA Global Hawk Pilots Face Challenges Flying Hurricane Missions

NASA's Hurricane and Severe Storm Sentinel, or HS3, the mission will be a complex one for the pilots flying NASA's Global Hawk aircraft from the ground. The mission, set to begin this month, will be the first deployment for the unmanned aircraft away from their regular base of operations at the Dryden Flight Research Center on Edwards Air Force Base, Calif. In addition, the pilots will be operating the aircraft from two locations on opposite coasts (Petrescu and Petrescu, 2009; 2011; 2012; 2013a, 2013b; 2013c).

After the upload of specialized science equipment is complete, the two GLOBAL Hawks will fly from one coast of the United States to another over sparsely populated areas and open water to reach NASA's Wallops flight facility in Virginia.

NASA Wallops was selected as a deployment site because the area of scientific interest is the Atlantic Ocean, especially the eastern Atlantic where hurricanes begin to form. Flights from the U.S. East Coast take less transit time to the target than those from NASA Dryden and allow the aircraft to travel further out over the Atlantic and collect data for a longer period of time.

Waiting at Wallops will be a mobile ground control center, mobile payload operations center and Ku-band satellite dish-all necessary for an operation of the highaltitude and long-endurance aircraft. Scientists, maintenance personnel and three pilots will support flights from Wallops.

During takeoff and landing of the Global Hawk, the aircraft must be in line-of-sight communications with the pilot. The pilots deployed to Wallops will manage this activity from the Global Hawk mobile operations facility, handing off operation of the aircraft to Dryden after reaching an altitude of approximately 30,000 feet.

Additional pilots sitting in Dryden's Global Hawk Operations Center will receive the verbal hand-off via telephone, cross check data links with pilots at Wallops and assume responsibility for the aircraft's operation until the mission is completed when the landing operation transfers back to Wallops. This close coordination alleviates the necessity to deploy a larger number of pilots. 


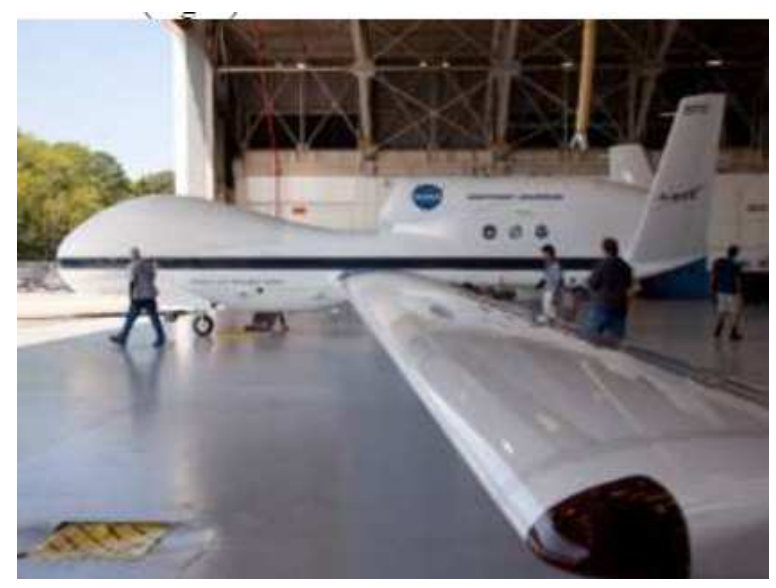

Fig. 5. This image captures a perspective of NASA's Global Hawk unmanned aircraft from one of the wings. The Global Hawk is sitting at the aircraft hangar of NASA's Wallops Flight Facility in Wallops Island, Va. on Sept. 7, 2012. Source: (Petrescu and Petrescu, 2013b)

When an unmanned aircraft is in the air, the groundbased pilots maintain continual contact with Federal Aviation Administration air traffic control specialists.

The interesting scenario for HS3 is that the pilots are in California's Mojave Desert, talking with East Coast controllers through a radio located on the aircraft. When flying in oceanic airspace, pilots talk with international controllers over a telephone. This communication is vital as air traffic controllers provide the altitude and number of other aircraft sharing the same area of the U.S.'s National Airspace System and international air space as the NASA aircraft. When the Global Hawk reaches an altitude of between 60,000 and 65,000 feet, there are few aircraft competing for space.

Although the flight path of the Global Hawk is preprogrammed into the aircraft's flight control computers prior to a mission, pilots are able to override the flight plan to accommodate the scientists' requests. The scientists will observe flights from the mobile payload operations facility at Wallops where information will stream onto computer monitors from their instruments. The payload manager at Wallops will send the scientists' request for a change in altitude or course to Dryden's mission director in the control room with the pilots at Dryden. The pilots operating the Global Hawk change the flight path by entering a new heading, airspeed or altitude on the primary flight display.

All Global Hawk pilots are rated to fly manned aircraft. The pilots commented that it is possible to become so engaged during a Global Hawk flight that it seems like a flying a manned aircraft. They add that much of the sensory information available to pilots of manned aircraft is missing for the unmanned aircraft pilots. It is not possible to smell the fuel, see the weather and terrain, hear the engine starting, or feel the movement from a ground control center. An unmanned aircraft pilot is dependent upon computers and their displays for updates on the health of the vehicle.

The Global Hawk pilots will have to deal with turbulence in the hurricane flights. Fortunately, the cruise altitude is above most of the unstable air associated with that weather phenomenon. In addition, an instrument measuring turbulence was adapted and will be installed with the science payload.

Global Hawk pilots will be well-prepared for the Hurricane and Severe Storm Sentinel mission. They spend hours planning missions, flying a simulator and have a support team in the "cockpit" consisting of a copilot, mission director and control room operator. Many are seasoned from flying this type aircraft for the military. Although their tools are a mouse, keyboard and computer displays, the NASA Global Hawk pilots find their work challenging and are proud of the job they do to support the U.S. science community.

\section{NATO}

In 2009, NATO announced that it expects to have a fleet of up to eight Global Hawks by 2012. The aircraft are to be equipped with MP-RTIP radar systems. NATO has budgeted US $\$ 1.4$ billion ( $€ 1$ billion) for the project and a letter of intent has been signed. NATO signed a contract for five Block 40 Global Hawks in May 2012.

\section{Luftwaffe}

The German Air Force (Luftwaffe) has ordered a variant of the RQ-4B equipped with German sensors, dubbed Euro Hawk. It combines a normal RQ-4B airframe with an EADS reconnaissance payload. The aircraft is based on the Block 20/30/40 RQ-4B but will be equipped with EADS' SIGINT package to fulfill Germany's desire to replace their aging Dassault-Breguet Atlantique electronic surveillance aircraft.

That sensor package comes in the form of six wings mounted pods, a first for the Global Hawk (Fig. 6).

The Euro Hawk was officially rolled out on October 8, 2009 and the first flight took place on June 29, 2010. It underwent several months of flight testing at Edwards Air Force Base before flying to Germany.

On July 21, 2011, the first Euro Hawk arrived in Manching, Germany where it will be equipped with the SIGINT sensor package (Petrescu and Petrescu, 2009; 2011; 2012; 2013a; 2013b; 2013c).

There it is also slated to undergo more testing and pilot training, until the first quarter of 2012, when it will be officially handed over to the Luftwaffe to be stationed with the Reconnaissance Wing 51.

The costs for the initial five aircraft are approx. $€ 430$ million for the development and $€ 430$ million for the actual procurement.

\section{Potential Operators}

Australia considered the purchase of a number of Global Hawk aircraft for maritime and land surveillance. 


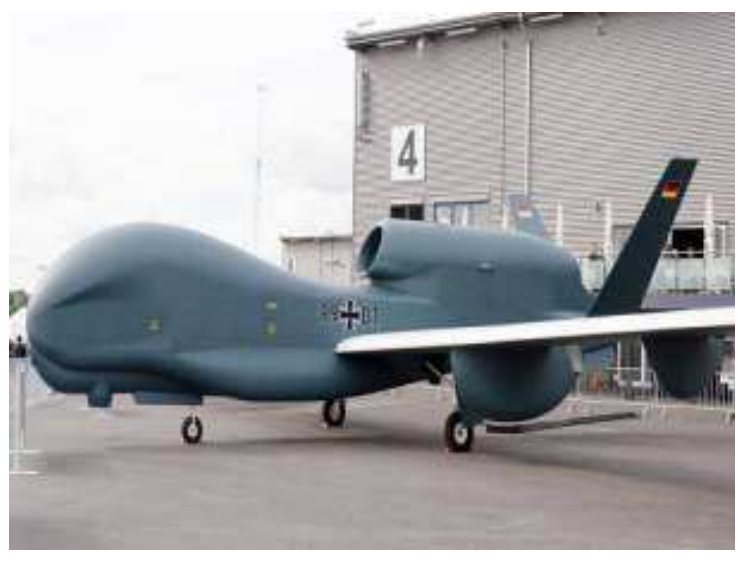

Fig. 6. Euro Hawk at the ILA 2012 Source: (Petrescu and Petrescu, 2013b)

The Global Hawk was to be assessed against the MQ9 Mariner in trials in 2007. The Global Hawk aircraft would have operated in conjunction with manned P-8A Poseidon aircraft by 10 and 11 Squadrons of the RAAF.

This combination, or a similar one, was to replace existing AP-3C Orion aircraft in 2018. In the end, the Australian government decided not to proceed with this plan and canceled the order.

Canada has also been a potential customer, looking at the Global Hawk for maritime and land surveillance as either a replacement for its fleet of CP-140 Aurora patrol aircraft or to supplement manned patrols of remote Arctic and maritime environments, before withdrawing from the joint effort in August 2011.

Spain has a similar requirement and has existing contacts with Northrop Grumman.

Japan has been reported as being interested in the purchase of three aircraft.

South Korea's Defense Acquisition Program Administration (DAPA) had expressed interest in acquiring at least four RQ-4B and support equipment by 2011 to increase the intelligence capabilities of the South Korean military after the return of the Wartime Operational Control from the U.S. to ROK and allocated approximately US\$19 million for evaluation purposes.

There was an ongoing debate among government officials on whether to take the US offer of Global Hawks or to press on with their domestic UAV development program.

In September 2011, the US and South Korea talked about deploying the aircraft near its border with North Korea to view North Korea and the North KoreaChina border.

In January 2012, DAPA announced that it was not proceeding with the purchase because the price had risen from US\$442M to US\$899M, far exceeding the budget allocation. DAPA stated that they were now investigating a purchase of either the Global Observer or the Phantom Eye.
The New Zealand Defence Force is keeping a "watching brief" over Global Hawk, which has the range to conduct surveillance in the Southern Ocean around Antarctica and in the Pacific Islands.

The acquisition process has not moved beyond an expression of interest. Also being looked at are the IAI Heron and the "Kahu", an indigenously developed handthrown drone.

The Indian Navy has expressed interest in acquiring six to eight MQ-4C Maritime Surveillance Unmanned Aircraft Systems.

Global Hawk could not benefit from a nuclear reactor engine due to the total cancellation of the USA nuclear power program for aircraft, in 1961, signed by President John Kennedy.

Global Hawk gets to the heart of what makes hurricanes tick.

Cutting-edge NASA technology has made this year's NASA Hurricane mission a reality. NASA and other scientists are currently flying a suite of state-ofthe-art, autonomously operated instruments that are gathering difficult-to-obtain measurements of wind speeds, precipitation and cloud structures in and around tropical storms.

"Making these measurements possible is the platform on which the instruments are flying," said Paul Newman, the deputy principal investigator of NASA's Hurricane and Severe Storm Sentinel (HS3), managed by NASA's Goddard Space Flight Center in Greenbelt, Md. HS3 will use NASA's unmanned Global Hawks, which are capable of flying at altitudes greater than 60,000 feet with flight durations of up to $28 \mathrm{~h}$ capabilities that increase the amount of data scientists can collect. "It's a brand-new way to do science," Newman said.

The month-long HS3 mission, which began in early September, is actually a more robust follow-on to NASA's Genesis and Rapid Intensification Processes (GRIP) experiment that scientists executed in 2010. Often referred to as "GRIP on steroids," HS3 is currently deploying one instrument-laden Global Hawk from the NASA Wallops Flight Facility on Virginia's Eastern Shore to look at the environment of tropical storms. In 2013 and 2014, a second Global Hawk will be added that will focus on getting detailed measurements of the inner core of hurricanes.

Without this new aircraft, developed originally for the U.S. Air Force to gather intelligence and surveillance data, the team says the mission wouldn't be possible.

The Global Hawk's ability to fly for a much longer period of time than manned aircraft will allow it to obtain previously difficult-to-get data. Scientists hope to use that data to gain new insights into how tropical storms form and more importantly, how they intensify into major Atlantic hurricanes-information that forecasters need to make better storm predictions, save lives and ultimately prevent costly coastal evacuations if a storm doesn't warrant them. 
"Because you can get to Africa from Wallops, we'll be able to study developing systems way out into the Atlantic," Newman explained. "Normal planes, which can fly for no more than about $10 \mathrm{~h}$, often miss the points where storms intensify," added Gerry Heymsfield, a Goddard scientist who used NASA Research and Development funding to create one of the mission's six instruments, the High-altitude Imaging Wind and Rain Airborne Profiler (HIWRAP). "With the Global Hawks, we have a much higher chance of capturing these events. Furthermore, we can sit on targets for a long time."

Just as important as the aircraft are the new or enhanced instruments designed to gather critical wind, temperature, humidity and aerosol measurements in the environment surrounding the storm and the rain and wind patterns occurring inside their inner cores, they added. "The instruments bring it all together," Newman said. "We didn't have these instruments 10 years ago."

The Global Hawk currently on deployment at Wallops is known as the "environmental" aircraft because it samples the environment in which hurricanes are embedded. It carries three instruments.

A Goddard-provided laser system called the Cloud Physics Lidar (CPL) is located in the nose. CPL measures cloud structures and aerosols, such as dust, sea salt particles and smoke particles, by bouncing laser light off these elements. An infrared instrument called the Scanning High-resolution Interferometer Sounder (SHIS), provided by the University of Wisconsin in Madison, sits in the belly of the aircraft. It measures the vertical profile of temperature and water vapor.

At the tail end is a drop sonde system provided by the National Center for Atmospheric Research and the National Oceanic and Atmospheric Administration. This system consists of 88 paper-towel-roll-sized tubes that are ejected much like a soda can in a vending machine. As the sensor drops, a parachute slows its descent, allowing the sensor to drift down through the storm while measuring winds, temperature, pressure and humidity.

In 2013 and 2014, working in tandem with its environmental counterpart will be a second Global Hawk, known as the "over-storm" aircraft. It will sample the internal structure of hurricanes. It, too, will carry three instruments.

Heymsfield's HIWRAP, for example, will be situated in the belly of the Global Hawk and will be responsible for sampling the cores of hurricanes.

Similar to a ground radar system, but pointed downward, HIWRAP measures the rain structure and winds, providing a three-dimensional view of these conditions.

Also, onboard this craft will be a microwave system called the High-Altitude MMIC Sounding Radiometer (HAMSR), created by NASA's Jet Propulsion Laboratory in Pasadena, Calif.

Located in the aircraft's nose, this instrument uses microwave wavelengths to measure temperature, water vapor and precipitation from the top of the storm to the surface.

At the other end of the aircraft in the tail section will be the Hurricane Imaging Radiometer (HIRAD) provided by NASA's Marshall Space Flight Center in Huntsville, Ala.

This microwave instrument measures surface wind speeds and rain rates in an unusual way. It collects this data by measuring the amount of "foaminess" in ocean waters. According to Newman, the amount of foaminess is proportional to wind speeds at the surface.

Although all six instruments measure different conditions, they share one important characteristic: all operate autonomously and deliver data to scientists in real-time another scientific advance. In the past, aircraft instruments, which often required the presence of a scientist to operate them, would record captured data.

Only after the aircraft landed could scientists begin evaluating what they had collected. With the Global Hawk, however, the data are transmitted to the ground in real-time. Should conditions warrant, the science team can direct the pilot, who flies the aircraft from a computer console on the ground, to change course or tweak the pre-programmed flight path in some way to maximize or improve the data they are gathering. "With the Global Hawk and these instruments, we can make better decisions," Heymsfield added.

The five-year mission will continue through 2014, at which time the team hopes to have dramatically improved their understanding of how storms intensify. "The insights we get will benefit forecasters," Newman said. "What we hope to do is take this technique and make it part of the operational forecast infrastructure."

The HS3 mission is supported by several NASA facilities including Wallops, Goddard, NASA's Dryden Flight Research Center at Edwards Air Force Base, Calif., Ames Research Center, Moffett Field, Calif.; Marshall Space Flight Center, Huntsville, Ala.; and the Jet Propulsion Laboratory, Pasadena, Calif.

In addition, the mission also involves collaborations with various partners from government agencies and academia. HS3 is an Earth Venture mission funded by NASA's Science Mission Directorate in Washington.

Earth Venture missions are managed by NASA's Earth System Science Pathfinder Program at NASA's Langley Research Center, Hampton, Va. The HS3 Project itself is managed by the Earth Science Project Office at NASA's Ames Research Center.

\section{Northrop Grumman B-2 Spirit}

The Northrop Grumman B-2 Spirit (also known as the Stealth Bomber) is an American strategic bomber, featuring low observable stealth technology designed for penetrating dense anti-aircraft defenses; it is able to deploy both conventional and nuclear weapons. 
The bomber has a crew of two and can drop up to eighty $500 \mathrm{lb}(230 \mathrm{~kg})$-class JDAM GPS-guided bombs, or sixteen 2,400 lb (1,100 kg) B83 nuclear bombs (Fig. 7), (Petrescu and Petrescu, 2009; 2011; 2012; 2013a; 2013b; 2013c).

The B-2 is the only aircraft that can carry large air-tosurface standoff weapons in a stealth configuration.

Development originally started under the "Advanced Technology Bomber" (ATB) project during the Carter administration and its performance was one of the reasons for his cancellation of the B-1 Lancer.

ATB continued during the Reagan administration, but worries about delays in its introduction led to the reinstatement of the B-1 program as well.

\section{Program Costs Rose Throughout Development}

Designed and manufactured by Northrop Grumman with assistance from Boeing, the cost of each aircraft averaged US\$737 million (in 1997 dollars).

Total procurement costs averaged $\$ 929$ million per aircraft, which includes spare parts, equipment, retrofitting and software support.

The total program cost including development, engineering and testing, averaged $\$ 2.1$ billion per aircraft in 1997.

Because of its considerable capital and operational costs, the project was controversial in the U.S. Congress and among the Joint Chiefs of Staff.

The winding-down of the Cold War in the latter portion of the 1980s dramatically reduced the need for the aircraft, which was designed with the intention of penetrating Soviet airspace and attacking high-value targets.

During the late 1980s and 1990s, Congress slashed initial plans to purchase 132 bombers to 21 .

In 2008, a B-2 was destroyed in a crash shortly after takeoff and the crew ejected safely.

A total of 20 B-2s remains in service with the United States Air Force.

Though originally designed primarily as a nuclear bomber, the B-2 was first used in combat to drop conventional bombs on Serbia during the Kosovo War in 1998 and saw continued use during the wars in Iraq and Afghanistan.

B-2s were also used during the 2011 Libyan civil war.

\section{Origins}

In the mid-1970s the search for a new US strategic bomber to replace the Boeing B-52 Stratofortress was underway, to no avail.

First, the B-70 and then the B-1A was canceled after only a few of each aircraft were built. The B-70 was intended to fly above and beyond defensive interceptor aircraft, only to find these same attributes made it especially vulnerable to surface-to-air missiles (SAMs).

The B-1 attempted to avoid SAMs by flying close to the ground to use terrain to mask its radar signature, only to face a new generation of interceptors with lookdown/shootdown capabilities that could attack them from above.

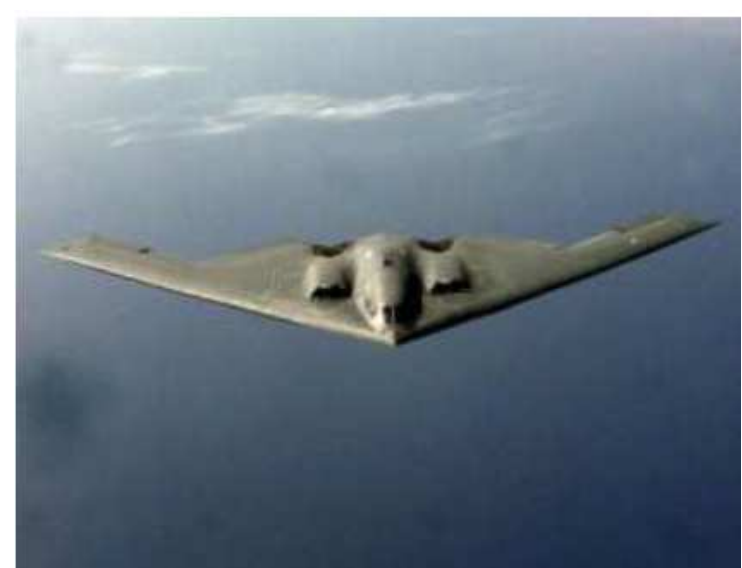

Fig. 7. Northrop Grumman B-2 Spirit. Source: (Petrescu and Petrescu, 2013b)

By the mid-1970s, it was becoming clear that there was a different way to avoid missiles and intercepts; known today as "stealth".

The concept was to build an aircraft with an airframe that deflected or absorbed radar signals so that little was reflected back to the radar unit.

An aircraft having stealth characteristics would be able to fly nearly undetected and could be attacked only by weapons and systems not relying on radar.

Although such possibilities existed such as human observation, their relatively short detection range allowed most aircraft to fly undetected by defenses, especially at night.

In 1974, DARPA requested information from US aviation firms about the largest radar cross-section of an aircraft that would remain effectively invisible to radars.

Initially, Northrop and McDonnell Douglas were selected for further development.

Lockheed had experience in this field due to developing the Lockheed A-12 and SR-71, which included a number of stealthy features, notably its canted vertical stabilizers, the use of composite materials in key locations and the overall surface finish in the radar-absorbing paint.

A key improvement was the introduction of computer models used to predict the radar reflections from flat surfaces where collected data drove the design of a "faceted" aircraft.

Development of the first such designs started in 1975 with "the hopeless diamond", a model Lockheed built to test the concept.

Plans were well advanced by the summer of 1975 when DARPA started the Experimental Survivability Testbed (XST) project.

Northrop and Lockheed were awarded contracts in the first round of testing. Lockheed received the sole award for the second test round in April 1976 leading to the Have Blue program. 


\section{ATB Program}

By 1976 these programs progressed to where a longrange strategic stealth bomber appeared viable.

Whereas the B-1 relied on flying around known defense sites and could only change its mission within a limited selection of pre-determined routes, a stealth bomber could fly over the Soviet Union undetected, allowing it to linger and hunt for targets rather than repeatedly entering and leaving the target zone as quickly as possible.

In a nuclear exchange, this strategy permits the aircraft to wait out the initial attacks and find targets that escaped destruction by eliminating the "overkill" that was built into existing war planning. Also, stealth characteristics negated prior requirements for highspeed dash capabilities and extensive electronic warfare suites for protection.

Carter was aware of these developments during 1977 and it appears to have been one of the major reasons the B-1 was canceled.

Further studies were ordered in early 1978 , by which point the Have Blue platform had flown and proven the concepts. During the 1980 presidential election in 1979 , Ronald Reagan repeatedly stated that Carter was weak on defense and used the B-1 as a prime example.

In return, on 22 August 1980, the Carter administration publicly disclosed that the United States Department of Defense (DoD) was working to develop stealth aircraft, including a bomber (Fig. 8).

The Advanced Technology Bomber (ATB) began in 1979. Full development of the black project followed and was funded under the code name "Aurora".

After the evaluations of the companies' proposals, the ATB competition was narrowed to the Northrop/Boeing and Lockheed / Rockwell teams with each receiving a study contract for further work.

Both teams used flying wing designs. Northrop had prior experience developing the YB-35 and YB-49 flying wing aircraft (Petrescu and Petrescu, 2009; 2011; 2012; 2013a; 2013b; 2013c).

The Northrop design was larger while the Lockheed design included a small tail.

The Northrop/Boeing team's ATB design was selected over the Lockheed/Rockwell design on 20 October 1981. The Northrop design received the designation B-2 and the name "Spirit".

The bomber's design was changed in the mid-1980s when the mission profile was changed from high-altitude to low-altitude, terrain-following.

The redesign delayed the B-2's first flight by two years and added about US\$1 billion to the program's cost.

An estimated US\$23 billion was secretly spent for research and development on the B-2 by 1989 .

MIT scientists helped assess the mission effectiveness of the aircraft under a five-year classified contract during the $1980 \mathrm{~s}$.

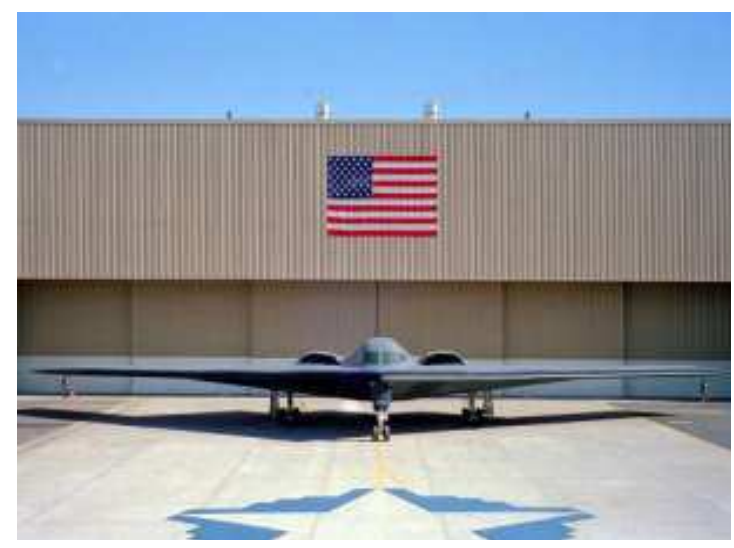

Fig. 8. The B-2's first public display in 1988. Source: (Petrescu and Petrescu, 2013b)

\section{Espionage}

Both during development and in service, there has been a considerable importance placed on the security of the B-2 and its technologies. Staff working on the B-2 in most if not all capacities has to achieve a level of special access clearance and undergo extensive background checks carried out by a special branch of the Air Force.

For the manufacturing, a former car plant in Pico Rivera, California was acquired and heavily rebuilt; the plant's employees were sworn to complete secrecy regarding their work. To avoid the possibility of suspicion, components were typically purchased through front companies, military officials would visit out of uniform and staff members were routinely subjected to polygraph examinations.

The secrecy extended so far that access to nearly all information on the program by both Government Accountability Office (GAO) and virtually all members of Congress itself was severely limited until the mid1980s. In 1984, a Northrop employee, Thomas Cavanaugh was arrested for attempting to sell classified information to the Soviet Union; the information was taken from Northrop's Pico Rivera, California factory. Cavanaugh was eventually sentenced to life in prison and released on parole in 2001.

The B-2 was first publicly displayed on 22 November 1988 at Air Force Plant 42, Palmdale, California, where it was assembled. This viewing was heavily restricted, guests were not allowed to see the rear of the B-2. However, Aviation Week editors found that there were no airspace restrictions over the presentation area and took photographs of the aircraft's then-secret platform and suppressed engine exhausts from above, to the USAF's disappointment. The B-2's first public flight was on 17 July 1989 from Palmdale (Fig. 9) (Petrescu and Petrescu, 2009; 2011; 2012; 2013a; 2013b; 2013c).

In October 2005 Noshir Gowadia, a design engineer who worked on the B-2's propulsion system, was arrested for selling B-2 related classified information to foreign countries. 


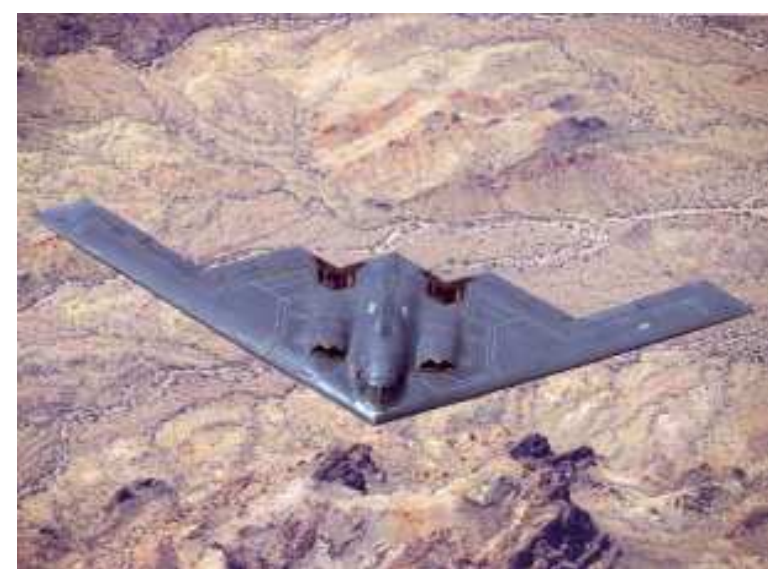

Fig. 9. The B-2's first public flight in 1989. Source: (Petrescu and Petrescu, 2013b)

On 9 August 2010 Gowadia was convicted in the United States District Court for the District of Hawaii on 14 of 17 charges against him.

On 24 January 2011, Gowadia was sentenced to 32 years in prison.

\section{Program Costs}

A procurement of 132 aircraft was planned in the mid-1980s but was later reduced to 75 .

By the early 1990s, the Soviet Union dissolved effectively eliminating the spirit's primary cold war mission.

Under budgetary pressures and Congressional opposition, in his 1992 State of the Union Address, President George H.W. Bush announced B-2 production would be limited to 20 aircraft.

In 1996, however, the Clinton administration, though originally committed to ending production of the bombers at 20 aircraft, authorized the conversion of a 21 st bomber, a prototype test model, to Block 30 fully operational status at a cost of nearly $\$ 500$ million.

In 1995, Northrop made a proposal to the USAF to build 20 additional aircraft with a flyaway cost of $\$ 566$ million each.

The program was the subject of public controversy for its cost to American taxpayers. In 1996, the General Accounting Office (GAO) disclosed that the USAF's B-2 bombers "will be, by far, the most costly bombers to operate on a per aircraft basis", costing over three times as much as the B-1B (US\$9.6 million annually) and over four times as much as the B-52H (\$US6.8 million annually).

In September 1997, each hour of B-2 flight necessitated $119 \mathrm{~h}$ of maintenance in turn. Comparable maintenance needs for the B-52 and the B-1B are 53 and $60 \mathrm{~h}$ respectively for each hour of flight.

A key reason for this cost is the provision of airconditioned hangars large enough for the bomber's $172 \mathrm{ft}$ $(52.4 \mathrm{~m})$ wingspan, which is needed to maintain the aircraft's stealthy properties, particularly its "lowobservable" stealthy skins.
Maintenance costs are about $\$ 3.4$ million a month for each aircraft.

The total "military construction" cost related to the program was projected to be US\$553.6 million in 1997 dollars.

The cost to procure each B-2 was US\$737 million in 1997 dollars, based only on a fleet cost of US\$15.48 billion.

The procurement cost per aircraft as detailed in GAO reports, which include spare parts and software support, was $\$ 929$ million per aircraft in 1997 dollars.

The total program cost projected through 2004 was US\$44.75 billion in 1997 dollars.

This includes development, procurement, facilities, construction and spare parts. The total program cost averaged US $\$ 2.13$ billion per aircraft.

The B-2 may cost up to $\$ 135,000$ per flight hour to operate in 2010, which is about twice that of the B-52 and B-1.

In its consideration of the fiscal year 1990 defense budget, the House Armed Services Committee trimmed $\$ 800$ million from the B-2 research and development budget, while at the same time staving off a motion to end the project.

Opposition in committee and in Congress was mostly broad and bipartisan, with Congressmen Ron Dellums (D-CA), John Kasich (R-OH) and John G. Rowland (RCT) authorizing the motion to end the project, others in the Senate, such as Jim Exon (D-NE) and John McCain (R-AZ), also opposing the project.

The escalating cost of the B-2 program and evidence of flaws in the aircraft's ability to elude detection by radar, were among factors that drove opposition to continue the program.

At the peak production period specified in 1989, the schedule called for spending US\$7 billion to $\$ 8$ billion per year in 1989 dollars, something Committee Chair Les Aspin (D-WI) said: "Won't fly financially."

In 1990, the Department of Defense accused Northrop of using faulty components in the flight control system; the threat posed by bird ingestion potentially damaging engine fan blades also required redesigning.

In time, a number of prominent members of Congress began to oppose the program's expansion, including former Democratic presidential nominee John Kerry, who cast votes against the B-2 in 1989, 1991 and 1992 while a US Senator, representing Massachusetts.

By 1992, Republican President George H.W. Bush called for the cancellation of the B-2 and promised to cut military spending by $30 \%$ in the wake of the collapse of the Soviet Union.

In May 1995, based on its 1995 Heavy Bomber Force Study, the DOD determined that additional B-2 procurements would exacerbate efforts to develop and implement long-term recapitalization plans for the U.S. Air Force bomber force. 
In October 1995, former Chief of Staff of the United States Air Force, General Mike Ryan and former Chairman of the Joint Chiefs of Staff, General John Shalikashvili, strongly recommended against Congressional action to fund the purchase of any additional B-2s, arguing that to do so would require unacceptable cuts in existing conventional and nuclearcapable aircraft and that the military had greater priorities in spending a limited budget.

Some B-2 advocates argued that procuring twenty additional aircraft would save money because B-2s would be able to deeply penetrate anti-aircraft defenses and use low-cost, short-range attack weapons rather than expensive standoff weapons.

However, in 1995, the Congressional Budget Office (CBO) and its Director of National Security Analysis, found that additional B-2s would reduce the cost of expended munitions by less than US\$2 billion in 1995 dollars during the first two weeks of a conflict, in which the Air Force predicted bombers would make their greatest contribution; a small fraction of the US $\$ 26.8$ billion (in 1995 dollars) life cycle cost that the CBO projected an additional $20 \mathrm{~B}-2 \mathrm{~s}$ would cost.

In 1997, as Ranking Member of the House Armed Services Committee and National Security Committee, Congressman Ron Dellums (D-CA), a long-time opponent of the bomber, cited five independent studies and offered an amendment to that year's defense authorization bill to cap production of the bombers to the existing 21 aircraft.

The amendment was narrowly defeated. Nonetheless, Congress did not approve funding for the purchase of any additional $\mathrm{B}-2$ bombers.

\section{Further Developments}

A number of upgrade packages have been applied to the B-2. In July 2008, the B-2's onboard computing architecture was extensively redesigned, it now incorporates a new Integrated Processing Unit (IPU) that communicates with systems throughout the aircraft via a newly-installed fiber optic network.

A new version of the operational flight program software was also developed, the legacy code was converted from the JOVIAL programming language used beforehand to $\mathrm{C}$.

Updates were also made to the weapon control systems to enable strikes upon non-static targets, such as moving ground vehicles (Fig. 10).

On 29 December 2008, Air Force officials awarded a US\$468 million contract to Northrop Grumman to modernize the B-2 fleet's radars.

Changing the radar's frequency was required as the US Department of Commerce has sold that radio spectrum to another operator.

In July 2009, it was reported that the B-2 had successfully passed a major USAF audit.

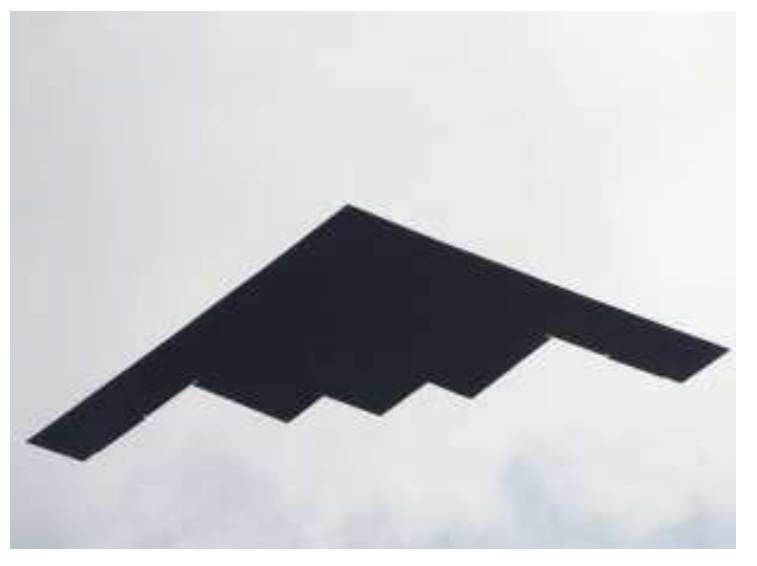

Fig. 10. B-2 Source: (Petrescu and Petrescu, 2013b)

In 2010, it was made public that the Air Force Research Laboratory had developed a new material to be used on the part of the wing trailing edge subject to engine exhaust, replacing existing material that quickly degraded.

In July 2010, political analyst Rebecca Grant speculated that when the B-2 becomes unable to reliably penetrate enemy defenses, the Lockheed Martin F-35 Lightning II may take on its strike/interdiction mission, carrying B61 nuclear bomb as a tactical bomber.

However, in March 2012, the Pentagon announced a $\$ 2$ billion, 10 year-long modernization of the B-2 fleet was to begin, these upgrades would be mainly focused on replacing outdated avionics and equipment.

It was reported in 2011 that the Pentagon was evaluating an unmanned stealth bomber, characterized as a "mini-B-2", as a potential replacement in the near future.

In 2012, Air Force Chief of Staff General Norton Schwartz stated the B-2's 1980s-era stealth would make it less survivable in future contested airspaces, so the USAF is to proceed with the Next-Generation Bomber despite overall budget cuts.

The Next-Generation Bomber was estimated, in 2012 , to have a projected overall cost of $\$ 55$ billion.

\section{Design}

The B-2 Spirit was developed to take over the USAF's vital penetration missions, able to travel deep into enemy territory to deploy their ordnance, which could include nuclear weapons.

The B-2 is a flying wing aircraft, meaning it has no fuselage or tail.

The blending of low-observable technologies with high aerodynamic efficiency and large payload gives the B-2 significant advantages over previous bombers.

Low observability provides a greater freedom of action at high altitudes, thus increasing both range and field of view for onboard sensors.

The U.S. Air Force reports its range as approximately 6,000 nautical miles $(6,900 \mathrm{mi} ; 11,000 \mathrm{~km})$. 
Due to the aircraft's complex flight characteristics and design requirements to maintain very low visibility to multiple means of detection, both the development and construction of the B-2 required the pioneering use of computer-aided design and manufacturing technologies (Fig. 11).

Northrop Grumman is the B-2's prime contractor; other contributing subcontractors include Boeing, Raytheon (formerly Hughes Aircraft), G.E. and Vought Aircraft.

The B-2 bears a resemblance to earlier Northrop aircraft, the YB-35 and YB-49 were both flying wing bombers that had been canceled in development in the early 1950s; allegedly for political reasons.

The B-2 has a crew of two: A pilot in the left seat and mission commander in the right; the $\mathrm{B}-2$ has provisions for a third crew member if needed.

For comparison, the B-1B has a crew of four and the B-52 has a crew of five.

The B-2 is highly automated and, unlike most twoseat aircraft, one crew member can sleep, use a toilet or prepare a hot meal while the other monitors the aircraft; extensive sleep cycle and fatigue research was conducted to improve crew performance on long sorties.

\section{Armaments and Equipment}

The B-2, in the envisaged Cold War scenario, was to perform deep-penetrating nuclear strike missions, making use of its stealthy capabilities to avoid detection and interception throughout missions.

There are two internal bomb bays in which munitions are stored either on a rotary launcher or two bomb-racks; the carriage of the weapons loadout internally results in less radar visibility than externally mounting of munitions.

Nuclear ordnance includes the B61 and B83 nuclear bombs; the AGM-129 ACM cruise missile was also intended for use on the B-2 platform.

It was decided, in light of the dissolution of the Soviet Union, to equip the B-2 for convention precision attacks as well as for the strategic role of nuclear strike.

The B-2 features a sophisticated GPS-Aided Targeting System (GATS) that uses the aircraft's APQ181 synthetic aperture radar to map out targets prior to deployment of GPS-aided bombs (GAMs), later superseded by the Joint Direct Attack Munition (JDAM).

In the B-2's original configuration, up to 16 GAMs or JDAMs could be deployed; an upgrade program in 2004 raised the maximum carriable capacity to 80 JDAMs.

The B-2 has various conventional weapons in its arsenal, able to equip Mark 82 and Mark 84 bombs, CBU-87 Combined Effects Munitions, GATOR mines and the CBU-97 Sensor Fuzed Weapon.

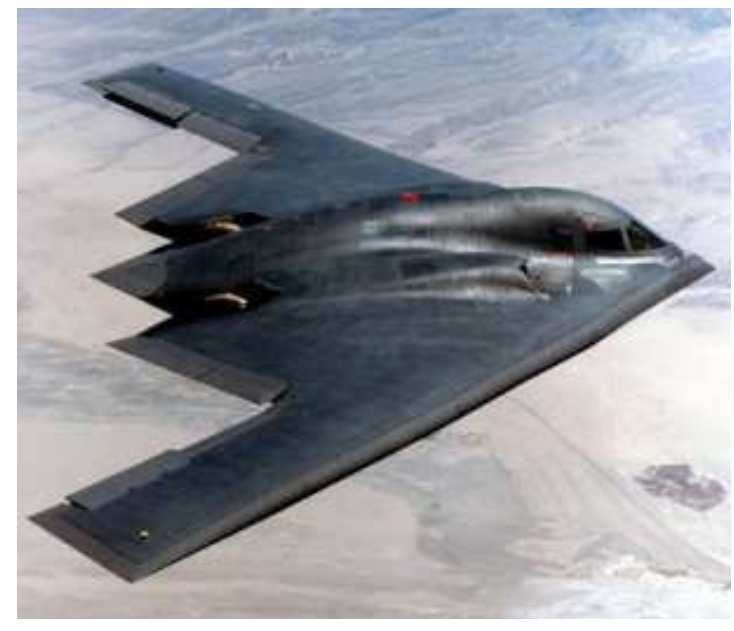

Fig. 11. Side view of a B-2 Spirit Source: (Petrescu and Petrescu, 2013b)

In July 2009, Northrop Grumman reported the B-2 was compatible with the equipment necessary to deploy the $30,000 \mathrm{lb}(14,000 \mathrm{~kg})$ Massive Ordnance Penetrator (MOP), which is intended to attack reinforced bunkers; up to two MOPs could be equipped in the B-2's bomb bays, the B-2 is the only platform compatible with the MOP as of 2012.

As of 2011, the AGM-158 JASSM cruise missile is an upcoming standoff munition to be deployed on the B2 and other platforms (Fig. 12) (Petrescu and Petrescu, 2009; 2011; 2012; 2013a; 2013b; 2013c).

\section{Systems}

In order to make the B-2 more effective than any previous bomber, it has integrated many advanced and modern avionics systems into its design, these have been modified and improved in light of the switch to conventional warfare missions.

The B-2 features the low probability of intercept AN/APQ-181 multi-mode radar, a fully digital navigation system that is integrated with terrain following radar and Global Positioning System (GPS) guidance and a Defensive Management System (DMS) to inform the flight crew against possible threats.

The onboard DMS is capable of automatically assessing the detection capabilities of identified threats and indicated targets (Fig. 13).

For safety and fault detection purposes, an onboard test system is interlinked with the majority of avionics on the B2 to continuously monitor the performance and status of thousands of components and consumables (Petrescu and Petrescu, 2009; 2011; 2012; 2013a; 2013b; 2013c).

It also provides Post-mission servicing instructions for ground crews.

In 2008, many of the standalone distributed computers on board the B-2, including the primary flight management computer, were being replaced by a single integrated system. 


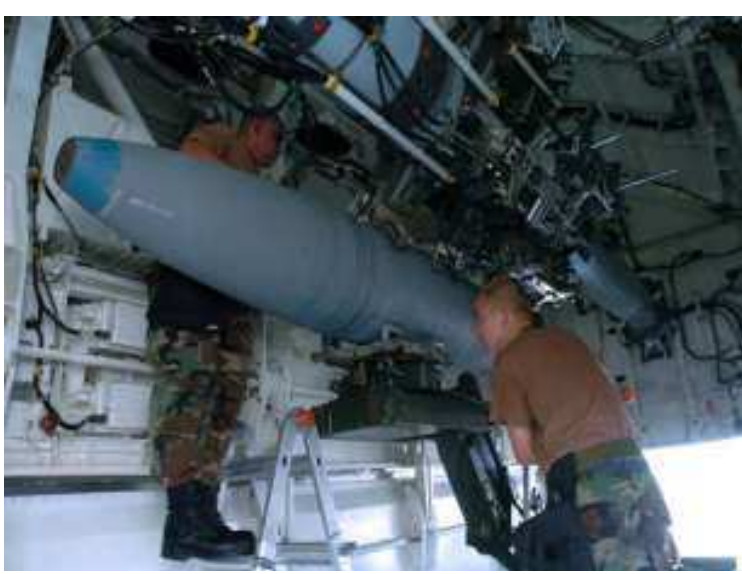

Fig. 12. A $2000 \mathrm{lb}$ BDU-56 bomb is being loaded onto a bomb bays rotary launcher, 2004 Source: (Petrescu and Petrescu, 2013b)

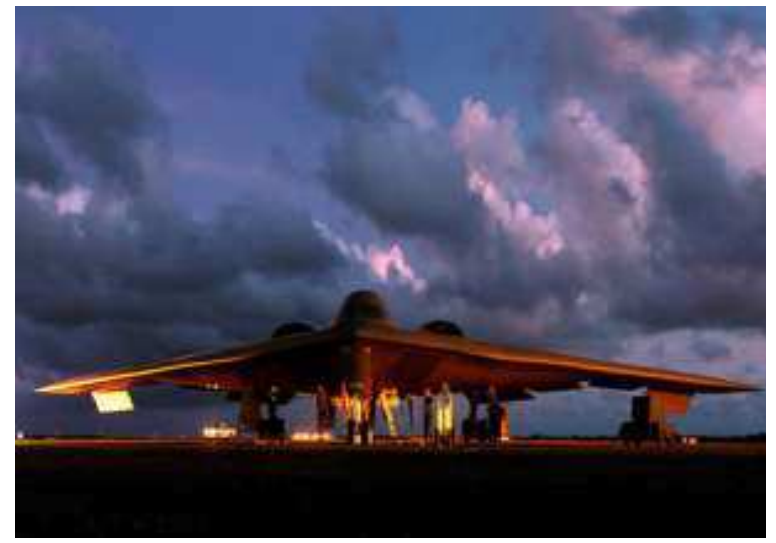

Fig. 13. An Air Force maintenance crew services a B-2 at Andersen AFB, Guam, 2004 Source: (Petrescu and Petrescu, 2013b)

In addition to periodic software upgrades and the introduction of new radar-absorbent materials across the fleet, the B-2 has had several major upgrades to its avionics and combat systems.

For battlefield communications, both Link-16 and a high-frequency satellite link have been installed, compatibility with various new munitions has been undertaken and the AN/APQ-181 radar's operational frequency was shifted in order to avoid interference with other operator's equipment.

The upgraded radar features entirely replaced arrays by those of a newer design, the AN/APQ-181 is now an Active Electronically Scanned Array (AESA) radar.

In order to address the inherent flight instability of a flying wing aircraft, the B-2 uses a complex quadruplex computer-controlled fly-by-wire flight control system, that can automatically manipulate flight surfaces and settings without direct pilot inputs in order to maintain aircraft stability.
The flight computer receives information on external conditions such as the aircraft's current airspeed and angle of attack via pitot-static sensing plates, as opposed to traditional pitot tubes which would negatively affect the aircraft's stealth capabilities.

The flight actuation system incorporates both hydraulic and electrical servo actuated components, it was designed with a high level of redundancy and fault diagnostic capabilities.

Northrop had investigated several means of applying directional control that would least infringe on the aircraft's radar profile, eventually settle on a combination of split brake-rudders and differential thrust.

Engine thrust became a key element of the B-2's aerodynamic design process early on; thrust not only affects drag and lift but pitching and rolling motions as well.

Four pairs of control surfaces are located along the wing's trailing edge; while most surfaces are used throughout the aircraft's flight envelope, the inner elevons are normally only in use at slow speeds, such as landing (Petrescu and Petrescu, 2009; 2011; 2012; 2013a; 2013b; 2013c).

To avoid potential contact damage during takeoff and to provide a nose-down pitching attitude, all of the elevons remain drooped during takeoff until a high enough airspeed has been attained.

\section{Stealth}

The B-2's low-observable, or "stealth", characteristics enable the safe penetration of sophisticated anti-aircraft defenses and to attack even heavily defended targets.

This stealth comes from a combination of reduced acoustic, infrared, visual and radar signatures to evade the various detection systems that could be used to detect and be used to direct attacks against an aircraft.

The majority of the B-2 is made out of a carbongraphic composite material that is stronger than steel and lighter than aluminum, perhaps most crucially it also absorbs a significant amount of radar energy. Reportedly, the B-2 Spirit has a radar signature of about $0.1 \mathrm{~m}^{2}$.

In contrast to the flat surfaces of the earlier F-117 Nighthawk, the B-2 is composed of many curved and rounded surfaces across its exposed airframe to deflect radar beams, additional reduction in its radar signature was achieved by the use of various Radar-Absorbent Materials (RAM) to absorb and neutralize radar beams.

The B-2's clean, low-drag flying wing configuration not only gave it exceptional range but was also beneficial to reducing its radar profile as well.

Another design feature is the placement of the engines, which are buried within the wing to conceal the engines' fans and minimize the thermal visibility of the exhaust.

The original design had tanks for a contrail-inhibiting chemical, but this was replaced in production aircraft by a contrail sensor that alerts the crew as to when they should change altitude. 
To reduce optical visibility during daylight operations, the B-2 is painted in an anti-reflective paint.

Innovations such as Alternate High-Frequency Material (AHFM) and automated material application methods were also incorporated into the aircraft to enhance its radar-absorbent properties and lower maintenance requirements (Aversa et al., 2016a; 2016b; 2016c; 2016d; 2016e; 2016f; 2016g; 2016h; 2016i; 2016j; 2016k; 2016l; 2016m; 2016n; 2016o; 2017a; 2017b; 2017c; 2017d; 2017e; Mirsayar et al., 2017).

In early 2004, Northrop Grumman began applying a newly-developed AHFM to operational B-2s.

In order to protect the operational integrity of its sophisticated radar absorbent material and coatings, each B2 is kept inside a climate-controlled hangar large enough to accommodate its 172-foot (52 m) wingspan (Fig. 14).

\section{Operational History}

The first operational aircraft, christened Spirit of Missouri, was delivered to Whiteman Air Force Base, Missouri, where the fleet is based, on 17 December 1993. The B-2 reached Initial Operational Capability (IOC) on 1 January 1997.

Depot maintenance for the B-2 is accomplished by U.S. Air Force contractor support and managed at Oklahoma City Air Logistics Center at Tinker Air Force Base. Originally designed to deliver nuclear weapons, modern usage has shifted towards a flexible role with conventional and nuclear capability.

The B-2's combat debut was in 1999, during the Kosovo War. It was responsible for destroying 33\% of selected Serbian bombing targets in the first eight weeks of U.S. involvement in the War. During this war, B-2s flew non-stop to Kosovo from their home base in Missouri and back. The B-2 was the first aircraft to deploy GPS satellite-guided JDAM "smart bombs" in combat use in Kosovo. The use of JDAMs and precisionguided munitions effectively replaced the controversial tactic of carpet-bombing, which had been harshly criticized due to it causing indiscriminate civilian casualties in prior conflicts, such as the 1991 Gulf War. On 7 May 1999, a B-2 accidentally deployed five JDAMs in a target building that was actually the Chinese Embassy, killing much staff.

The B-2 saw service in Afghanistan, striking ground targets in support of Operation Enduring Freedom. With aerial refueling support, the B-2 flew one of its longest missions to date from Whiteman Air Force Base, Missouri to Afghanistan and back (Fig. 15).

The B-2's combat use preceded a U.S. Air Force declaration of "full operational capability" in December 2003.

The Pentagon's Operational Test and Evaluation 2003 Annual Report noted that the B-2's serviceability for the fiscal year 2003 was still inadequate, mainly due to the maintainability of the B-2's low observable coatings.

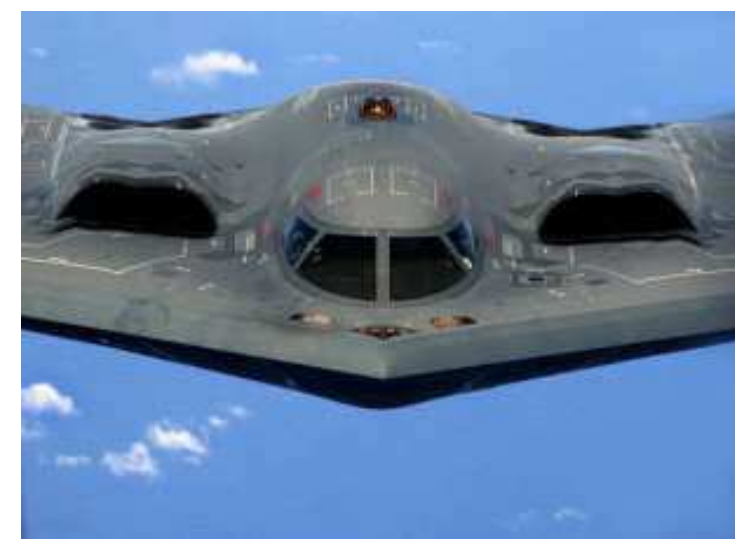

Fig. 14. The B-2's engines are buried within its wing to conceal the engines' fans and minimize their exhaust signature. Source: (Petrescu and Petrescu, 2013b)

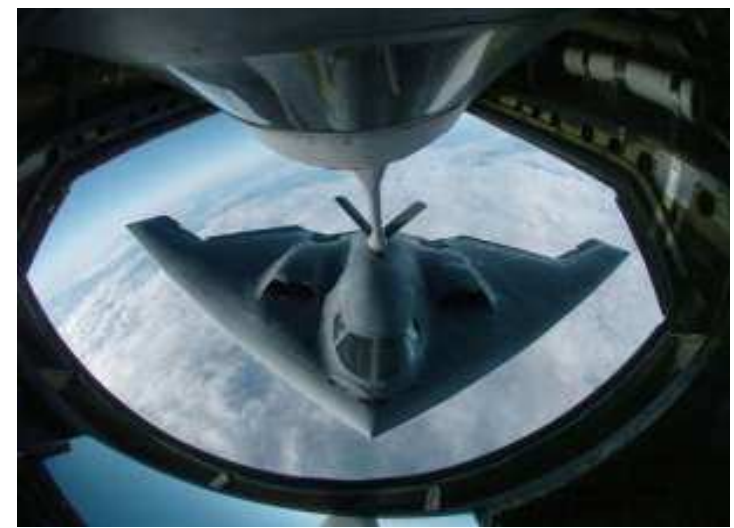

Fig. 15. A B-2 during aerial refueling which extends its range past 6,000 nautical miles $(6,900 \mathrm{mi} ; 11,000 \mathrm{~km})$ for intercontinental sorties. Source: (Petrescu and Petrescu, 2013b)

The evaluation also noted that the Defensive Avionics suite also had shortcomings with "pop-up threats".

During the Iraq War (Operation Iraqi Freedom), B-2s operated from Diego Garcia and an undisclosed "forward operating location".

Other sorties in Iraq have launched from Whiteman AFB. This resulted in missions lasting over $30 \mathrm{~h}$ and one mission of over $50 \mathrm{~h}$. "Forward operating locations" have been previously designated as Andersen Air Force Base in Guam and RAF Fairford in the UK, where new climate controlled hangars have been constructed.

B-2s have conducted 27 sorties from Whiteman AFB and 22 sorties from a forward operating location, releasing more than 1.5 million pounds of munitions, including 583 JDAM "smart bombs" in 2003.

In response to organizational issues and high-profile mistakes made within the Air Force; all of the B-2s, along with the nuclear-capable B-52s and the Air Force's Intercontinental Ballistic Missiles (ICBMs) were transferred to the newly-formed Air Force Global Strike Command on 1 February 2010. 
In March 2011, B-2s were the first US aircraft into action in Operation Odyssey Dawn, the UN mandated enforcement of the Libyan no-fly zone.

Three B-2s dropped 40 bombs on a Libyan airfield in support of the UN no-fly zone (Fig. 16).

The B-2s flew directly from the US mainland, being refueled by allied tanker aircraft twice on the inbound journey and twice again on the way back across the Atlantic.

In August 2011, The New Yorker reported that prior to the May 2011 US special forces raid in Abbottabad, Pakistan that resulted in the Death of Osama bin Laden, US officials had considered an airstrike by one or more $\mathrm{B}-2 \mathrm{~s}$ as an alternative; an airstrike was rejected due to concerns of damage to surrounding civilian buildings.

No operational B-2s have been retired by the Air Force to be put on display. However, B-2s have made periodic appearances on ground display at various air shows.

B-2 test article (s/n AT-1000), the second of two built without engines or instruments for static testing, was placed on display in 2004 at the National Museum of the United States Air Force near Dayton, Ohio.

The test article passed all structural testing requirements before the airframe failed.

The Museum's restoration team spent over a year reassembling the fractured airframe.

The display airframe is marked to resemble the spirit of Ohio (S/N 82-1070), the B-2 used to test the design's ability to withstand extreme heat and cold. The exhibit features the actual Spirit of Ohio nose wheel door, with its distinctive Fire and Ice artwork, which was painted and signed by the technicians who performed the temperature testing.

The restored test aircraft is on display in the museum's "Cold War Gallery" (Fig. 17).

From 1989 to 2004, the South Dakota Air and Space Museum located on the grounds of Ellsworth Air Force Base displayed the 10-short-ton (9-metric-ton) "HondaStealth", a $60 \%$ scale mock-up of a stealthy bomber which had been built by North American Honda in 1988 for an advertising campaign.

Although not an actual replica of a B-2, the mock-up was close enough to the B-2's design to arouse suspicion that Honda had intercepted classified, top secret information, as the B-2 project was still officially classified in 1988.

Honda donated the model to the museum in 1989 , on condition that the model is destroyed if it was ever replaced with a different example. In 2005, when the museum received a B-1 Lancer for display (Ellsworth being a B-1 base), the museum destroyed the mock-up:

- General characteristics

- Crew: 2

- Length: $69 \mathrm{ft}(21.0 \mathrm{~m})$

- Wingspan: $172 \mathrm{ft}(52.4 \mathrm{~m})$
- Height: $17 \mathrm{ft}(5.18 \mathrm{~m})$

- Wing area: $5,140 \mathrm{ft}^{2}\left(478 \mathrm{~m}^{2}\right)$

- Empty weight: $158,000 \mathrm{lb}(71,700 \mathrm{~kg})$

- Loaded weight: $336,500 \mathrm{lb}(152,200 \mathrm{~kg})$

- Max. takeoff weight: $376,000 \mathrm{lb}(170,600 \mathrm{~kg})$

- Power plant: $4 \times$ General Electric F118-GE-100 non after burning turbofans, 17,300 lbf $(77 \mathrm{kN})$ each

- Fuel capacity: 167,000 pounds (75, $750 \mathrm{~kg})$ performance

- Maximum speed: Mach 0.95 (550 knots, $630 \mathrm{mph}$, $1,010 \mathrm{~km} / \mathrm{h}$ ) at $40,000 \mathrm{ft}$ altitude/Mach 0.95 at sea level [118]

- Cruise speed: Mach 0.85[58] (487 knots, $560 \mathrm{mph}$,

- $900 \mathrm{~km} / \mathrm{h})$ at $40,000 \mathrm{ft}$ altitude

- $\quad$ Range: 6,000 nmi (11,100 km (6,900 mi))

- $\quad$ Service ceiling: $50,000 \mathrm{ft}(15,200 \mathrm{~m})$

- Wing loading: $67.3 \mathrm{lb} / \mathrm{ft}^{2}\left(329 \mathrm{~kg} / \mathrm{m}^{2}\right)$

- Thrust/weight: 0.205

- Armament

- 2 internal bays for $50,000 \mathrm{lb}(23,000 \mathrm{~kg})$

- $80 \times 500$ lb class bombs (Mk-82) mounted on Bomb

- Rack Assembly (BRA)

- $\quad 36 \times 750 \mathrm{lb}$ CBU class bombs on BRA

- $16 \times 2000 \mathrm{lb}$ class weapons (Mk-84, JDAM-84,

- JDAM-109) mounted on Rotary Launcher Assembly

- (RLA) $16 \times$ B61 or B83 nuclear weapons on RLA (Fig. 18)

The U.S. Air Force's B-2 stealth bomber is the flagship of the nation's long-range strike arsenal and one of the most survivable aircraft in the world. Its unique capabilities, including its stealth characteristics, allow it to penetrate the most sophisticated defenses and hold at risk high value, heavily defended enemy targets.

The B-2 has demonstrated its capabilities in several combat scenarios, most recently during Operation Iraqi Freedom.

The B-2 is the only U.S. aircraft that combines long range, large payload and stealth in a single platform, giving it the ability to project air power anywhere in the world.

It can fly more than 6,000 nautical miles unrefueled and more than 10,000 nautical miles with just one aerial refueling. With its ability to carry more than 20 tons of conventional and nuclear ordnance and deliver it precisely under any weather conditions, the B-2 also has the ability to change the outcome of a conflict with a single mission.

Northrop Grumman, the B-2 prime contractor, leads an industry team that is working with the Air Force to modernize the B-2 to ensure that it remains fully mission capable against evolving worldwide threats.

A range of upgrade programs are improving the B-2's lethality; its ability to collect, process and disseminate battlefield information with joint force commanders or other local first responders worldwide; and its ability to receive updated target information during a mission. 


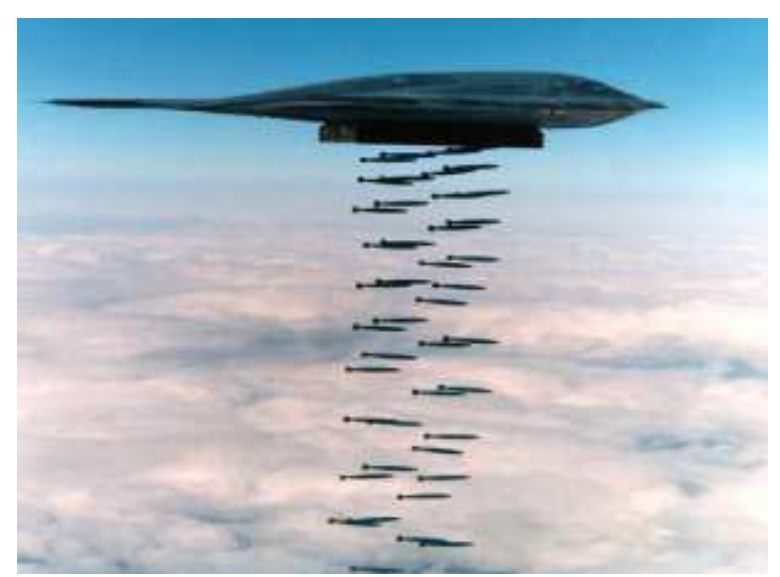

Fig. 16. In a 1994 live fire exercise near Point Mugu, California, a B-2 drops $47500 \mathrm{lb}(230 \mathrm{~kg})$ class Mark 82 bombs, which is more than half of a B-2's total ordnance payload. Source: (Petrescu and Petrescu, 2013b)

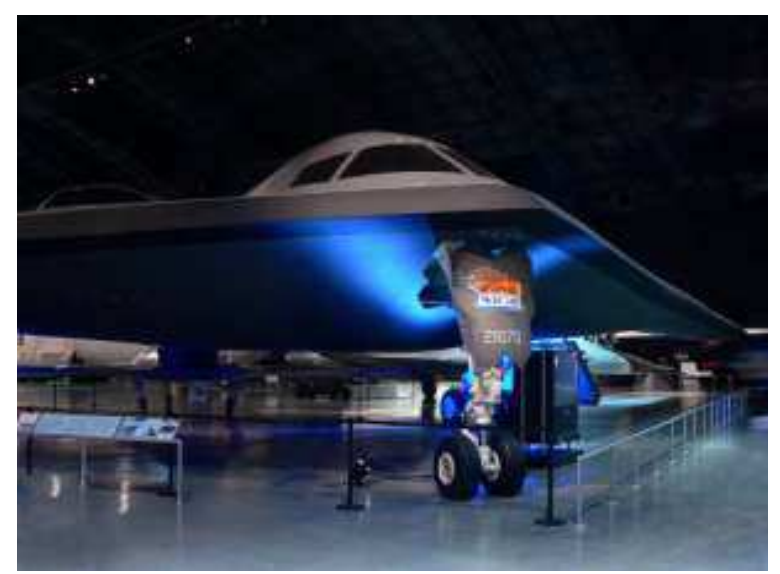

Fig. 17. A B-2 Spirit on display at the National Museum of the United States Air Force. Source: (Petrescu and Petrescu, 2013b)

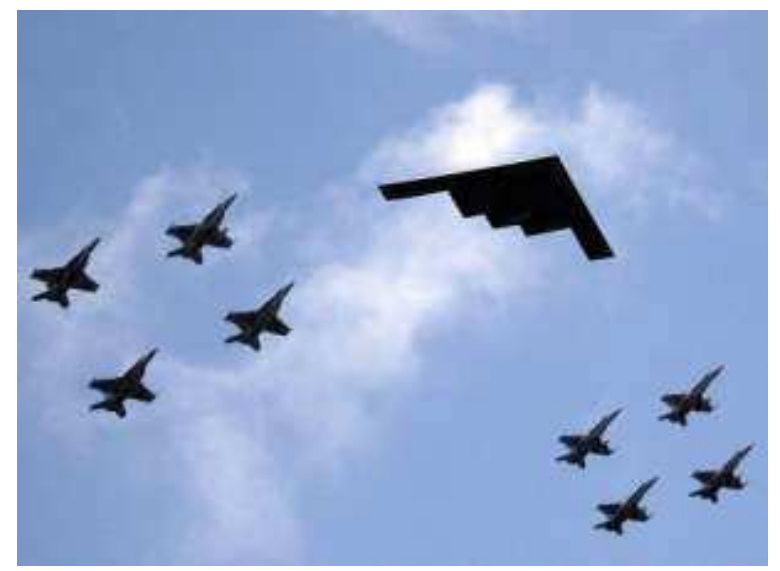

Fig. 18. A B-2 in formation flight with 8 US Navy McDonnell Douglas F/A-18 Hornets. Source: (Petrescu and Petrescu, 2013b)
Twenty-one aircraft were built in the original B-2 fleet. Today, the fleet consists of 20 aircraft, following the loss, in February 2008, of the Spirit of Kansas, which crashed while taking off from Andersen Air Force Base, Guam, the first such incident in the B-2's 19 years of operation. Since 1989, B-2 aircraft have flown more than 14,000 sorties and accumulated more than 75,000 flying hours without incident, an unprecedented safety record.

Nineteen B-2s are currently based at Whiteman Air Force Base, Mo., home of the 509th Bomb Wing, while one aircraft is assigned to flight testing at Edwards AFB, Calif. to validate software and weapon systems upgrades.

The B-2 Spirit is a multi-role bomber capable of delivering both conventional and nuclear munitions.

A dramatic leap forward in technology, the bomber represents a major milestone in the U.S. bomber modernization program.

The B-2 brings massive firepower to bear, in a short time, anywhere on the globe through previously impenetrable defenses.

Along with the B-52 and B-1B, the B-2 provides the penetrating flexibility and effectiveness inherent in manned bombers. Its low-observable, or "stealth," characteristics give it the unique ability to penetrate an enemy's most sophisticated defenses and threaten its most valued and heavily defended, targets. It's its capability to penetrate air defenses and threaten effective retaliation provide a strong, effective deterrent and combat force well into the 21 st century.

The revolutionary blending of low-observable technologies with high aerodynamic efficiency and large payload gives the B-2 important advantages over existing bombers.

Its low-observe ability provides it greater freedom of action at high altitudes, thus increasing its range and a better field of view for the aircraft's sensors. Its unrefueled range is approximately 6,000 nautical miles $(9,600 \mathrm{~km})$.

The B-2's low observability is derived from a combination of reduced infrared, acoustic, electromagnetic, visual and radar signatures. These signatures make it difficult for the sophisticated defensive systems to detect, track and engage the B-2.

Many aspects of the low-observability process remain classified; however, the B-2's composite materials, special coatings and flying-wing design all contribute to its "stealthiness."

The B-2 has a crew of two pilots, an aircraft commander in the left seat and mission commander in the right, compared to the B-1B's crew of four and the B-52's crew of five. The first B-2 was publicly displayed on Nov. 22, 1988, when it was rolled out of its hangar at Air Force Plant 42, Palmdale, Calif. Its first flight was July 17, 1989. 
The B-2 Combined Test Force, Air Force Flight Test Center, Edwards AFB, Calif., is responsible for flight testing the Engineering, Manufacturing and Development aircraft as they are produced.

Five of the six developmental aircraft delivered to Edwards are still involved in continuing flight testing. The first test aircraft is currently kept in flyable storage. Whiteman AFB, Mo., is the B-2's only operational base.

The first aircraft, Spirit of Missouri, was delivered Dec. 17, 1993. Primary maintenance responsibility for the B-2 is divided between Oklahoma City Air Logistics Center at Tinker AFB, Okla. for avionics software (contractor); Ogden Air Logistics Center, Hill AFB, Utah for landing gear and trainers (contractor); and the Northrop-Grumman facility at Air Force Plant 42 at Palmdale for periodic depot maintenance.

The prime contractor, responsible for overall system design and integration, is Northrop Grumman's B-2 Division. Boeing Military Airplanes Co., Vought Aircraft Co., Hughes Radar Systems Group and General Electric Aircraft Engine Group are key members of the aircraft contractor team. Another major contractor, responsible for aircrew training devices (weapon system trainer and mission trainer) is Hughes Training Inc. (HTI) - Link Division, formerly known as C.A.E. - Link Flight Simulation Corp. Northrop-Grumman and its major subcontractor HTI, excluding Link Division, is responsible for developing and integrating all aircrew and maintenance training programs.

\section{B-2 Spirit at the 2005 Edwards AFB Air Show}

It was disappointing when we heard over the radio scanner on Saturday that the B-2 Spirit display had been canceled because of mechanical problems, especially since I'd heard that the Edwards show is one of the very few places where it's possible to see the B-2 banking at close range.

To be honest, we'd been hearing its engines behind us for quite some time and we could see people working on it, so it didn't come as a total surprise when the cancellation came through.

However, shortly afterward there was the B-2 taxying out for its performance and it turns out that the only problem had been a broken motor shaft for the crew entry ladder! In this photo, not only can you see the "stealth bomber", but on the other side of the field in the static display area you can see the F-117 "stealth fighter", which really should be the A-117 "stealth strike plane", especially now that a true stealth fighter in the form of the F-22 Raptor is in service (Fig. 19).

Here's the extraordinary beast on its takeoff run; with no vertical tail it looks completely other-worldly, but it actually flies much like any other more conventional aircraft.

This one is called "The Spirit of New York" and is based here at Edwards rather than at Whiteman Airforce base in Missouri, which is the only operational base for them in the continental United States.

You can see that they've put the Edwards "ED" tail code on the landing gear door since there's no tail to put it on (Fig. 20)!

The unusual scoops on top of the engine pods are auxiliary air intakes which are needed to get extra air flow into the engines at low speeds.

They're rather similar to the auxiliary intakes on top of Russian fighters, but the purpose is different, the Russians using theirs to reduce the probability of damage from ingesting foreign objects on the runway during takeoff.

This particular aircraft is the only flight test B-2 and it's unusual in another way, too - the stenciling on the undercarriage doors was screwed up and so the letters lean the opposite way to all other B-2s (Fig. 21).

With no tail, the stealth bomber relies on the control surfaces along the rear of the wing to minimize sidetoside yawing motion; you can see one of those control surfaces deployed here (Fig. 22).

During a mission, these control surfaces would make the aircraft more visible to radar, so it's thought that yaw is then eliminated by the onboard computer systems applying differing thrusts from the engines on either side.

The funny looking "beaver tail" at the tail end of the aircraft is called the GLAS or "gust load alleviation surface", an on-board computer uses it to smooth out the ride when sensors at the front of the plane detect vertical gusts.

The four non-afterburning engines are buried within the wing. Apart from everything else, this makes the aircraft very quiet, it just whispers past you even at low altitude (Fig. 23).

Flying wings are very efficient aerodynamically, with much less drag than ordinary aircraft. The B-2 likes to get into the air and is a little reluctant to come down, so the crews actually put some effort into forcing the plane on a downward trajectory when landing, much like naval aviators flying onto aircraft carriers (Fig. 24).

This angle shows off the unusual air intakes, which are mounted far back on top of the wing and have an unusual angled shape, all in order to reduce the radar cross section of the plane.

Jet turbine compressor blades have a nasty tendency to "twinkle" on radar screens as they spin, so the air duct is " $\mathrm{S}$ " shaped so the blades aren't visible from any angle.

On the F-117 Nighthawk, the compressor blades are hidden by metal mesh at the front of the intakes, but this isn't an ideal solution since it impedes the airflow (Fig. 25).

There's no drag chute, but one of the B-2's design criteria was the ability to operate from any airfield useable by a 727 airliner, so the rudders are used as air brakes to slow the aircraft down (Fig. 26).

This design feature was also used on Northrop's earlier flying wing bombers and it's referred to as a "rudder on" or "deceleration" because the same panels which are deflected apart to decelerate the plane are also moved in tandem to act as rudders or ailerons. 


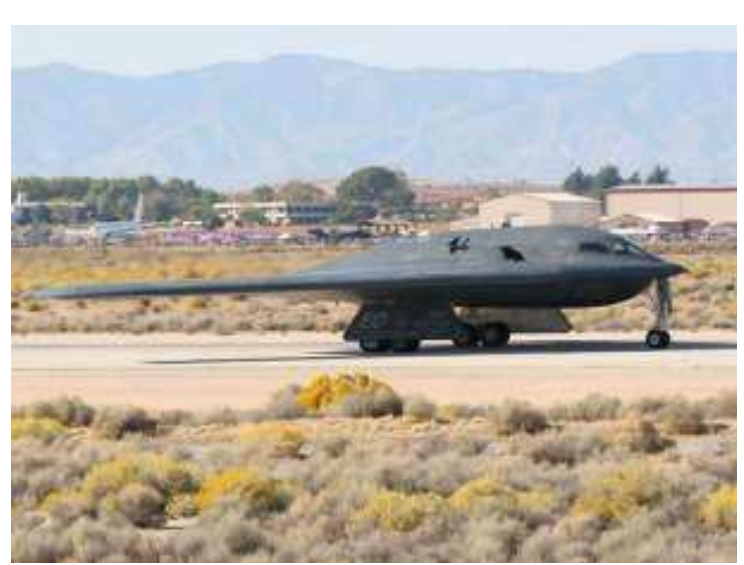

Fig. 19. B-2 Spirit at the 2005 Edwards AFB Air Show. Source: (Petrescu and Petrescu, 2013b)

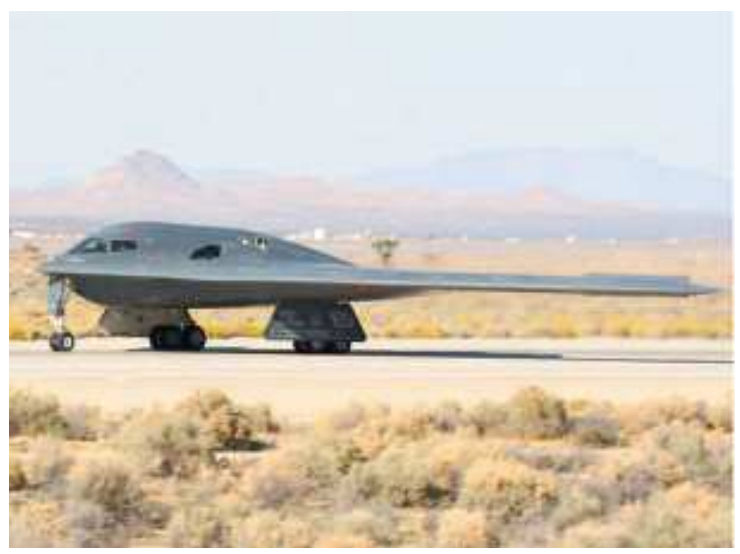

Fig. 20. The Spirit of New York". Source: (Petrescu and Petrescu, 2013b)

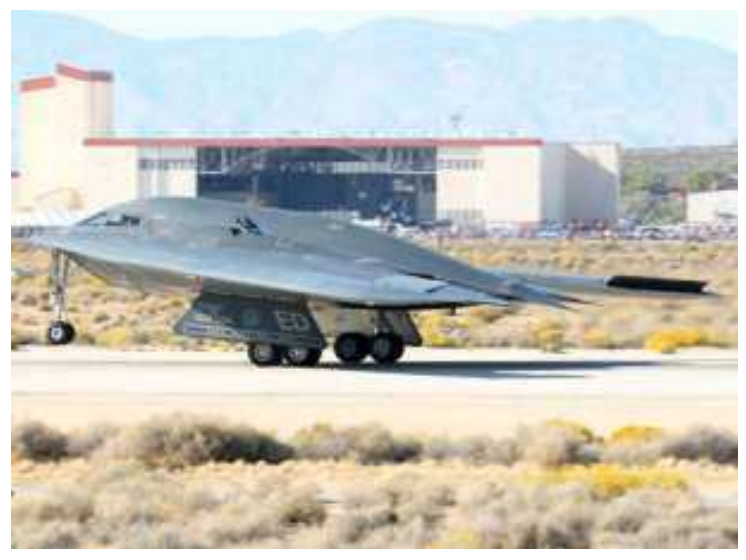

Fig. 21. The unusual scoops on top of the engine pods are auxiliary air intakes which are needed to get extra air flow into the engines at low speeds. Source: (Petrescu and Petrescu, 2013b)

As the 1960s progressed, the US Air Force was working to find a replacement for the Boeing B-52 Stratofortress.

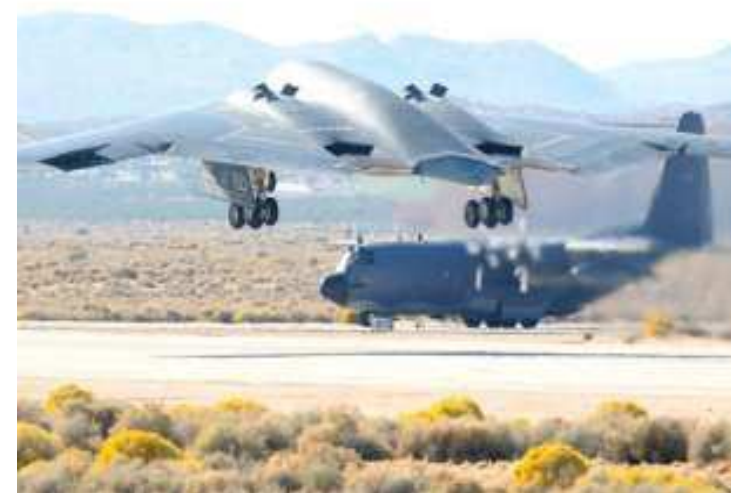

Fig. 22. With no tail, the stealth bomber relies on the control surfaces along the rear of the wing to minimize sideto-side yawing motion. Source: (Petrescu and Petrescu, 2013b)

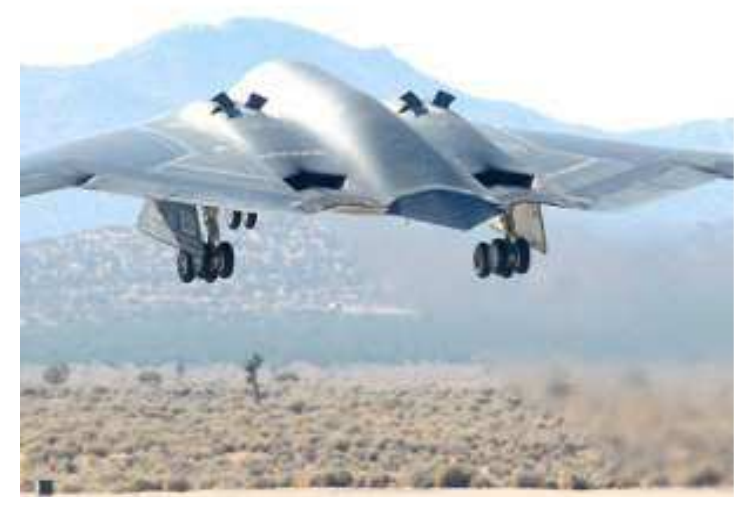

Fig. 23. The four non-afterburning engines are buried within the wing. Source: (Petrescu and Petrescu, 2013b)

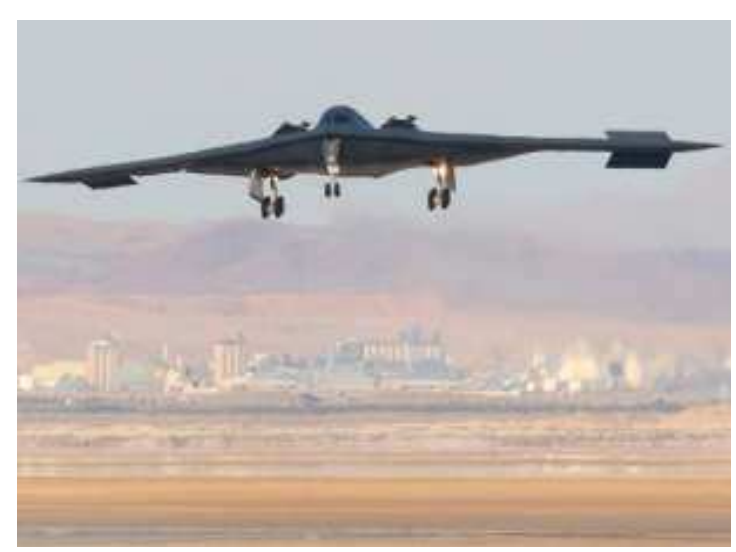

Fig. 24. Flying wings are very efficient aerodynamically, with much less drag than ordinary aircraft. Source: (Petrescu and Petrescu, 2013b)

While still the service's primary nuclear bomber, the aircraft was also in use during the Vietnam War dropping conventional munitions. 


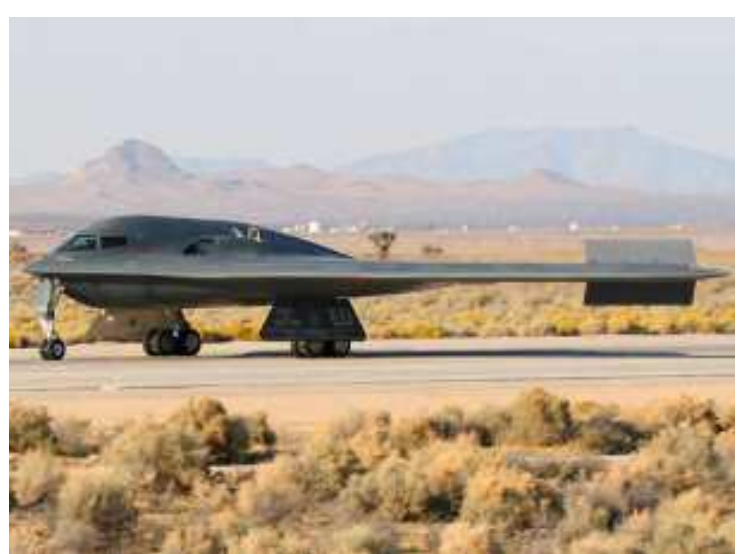

Fig. 25. This angle shows off the unusual air intakes, which are mounted far back on top of the wing and have an unusual angled shape, all in order to reduce the radar cross section of the plane. Source: (Petrescu and Petrescu, 2013b)

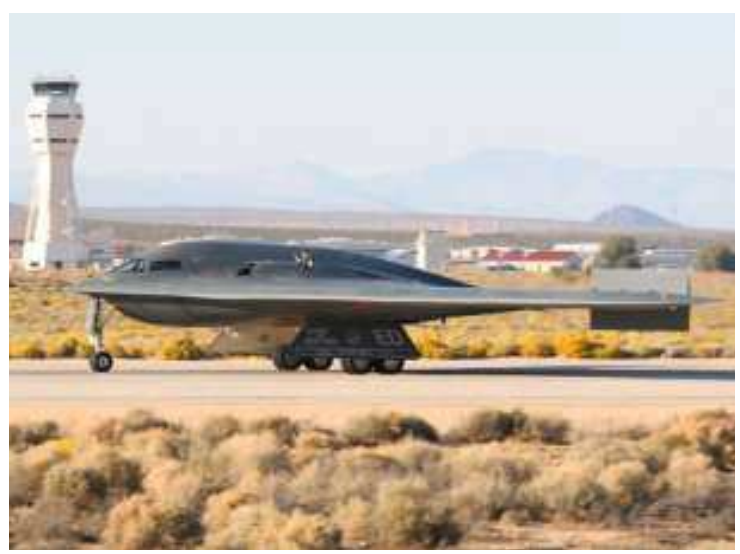

Fig. 26. There's no drag chute, but one of the B-2's design criteria was the ability to operate from any airfield useable by a 727 airliner, so the rudders are used as air brakes to slow the aircraft down. Source: (Petrescu and Petrescu, 2013b)

With the failure of the XB-70 Valkyrie project, emphasis shifted towards the aircraft that would become the Rockwell B-1 Lancer. As work moved forward on this project in the early 1970s, the Defense Advanced Research Projects Agency (DARPA), began requesting information regarding technologies that could deflect or absorb radar signals.

It was believed that if these technologies could be incorporated into an aircraft, it would be impervious to surface-to-air missiles and other radar-based methods of interception. Covertly approaching the aircraft industry in 1974, DARPA selected McDonnell Douglas and Northrop to push forward developing a "stealth" bomber project.

Also included in the discussions was Lockheed as the company had incorporated stealth features into its SR-71 Blackbird spy plane and was currently working on the stealth fighter project that would produce the F-117 Nighthawk.

By 1976, Lockheed's stealth testing, as part of the Have Blue Project, led to the belief that a large stealth bomber could be created. Additional studies followed in 1978 and the following year the Advanced Technology Bomber (ATB) program was initiated.

A fully black project, ATB received proposals from combined teams at Lockheed-Rockwell and NorthropBoeing. In creating ATB designs, both teams elected to utilize a flying wing configuration.

On October 20, 1981, the design from Northrop was selected and designated B-2 Spirit.

Flown by a crew of two, Northrop's design was powered by four General Electric F118-GE-100 engines which were situated deep within the B-2's wing to minimize their radar and infrared signatures. The B-2's minimal radar signature (approx. 0.1 square $\mathrm{m}$ ) was achieved through the use of a variety of composite materials, special coatings and the aircraft's shape.

By utilizing a flying wing design, Northrop eliminated many of the leading edges which could make the bomber visible to radar.

Capable of flying approximately 6,900 miles, the B-2 was designed for long duration missions and includes a toilet and small kitchen facility.

As computers control many of the aircraft's systems, only one crew member needs to be on duty at a time, allowing the other to sleep or perform other tasks.

Possessing a large payload, the B-2 can carry up to eight $500 \mathrm{lb}$. JDAM GPS-guided bombs or sixteen B83 nuclear bombs.

In addition, it is capable of carrying a variety of standoff weapons such as cruise missiles.

Targeting is aided by the aircraft's APQ-181 radar which can correct GPS errors and increase accuracy.

While a black project, the existence of the B-2's development was hinted at by President Jimmy Carter during the 1980 presidential election.

The aircraft was first publically displayed on November 22, 1988, at Air Force Plant 42 in Palmdale, CA, with its first public flight taking place on July 17 of the following year. The B-2 Spirit is a multi-role bomber capable of delivering both conventional and nuclear munitions.

Along with the $\mathrm{B}-52$ and $\mathrm{B}-1 \mathrm{~B}$, the $\mathrm{B}-2$ provides the penetrating flexibility and effectiveness inherent in manned bombers. Its low-observable, or "stealth," characteristics give it the unique ability to penetrate an enemy's most sophisticated defenses and threaten its most valued and heavily defended, targets.

It's its capability to penetrate air defenses and threaten effective retaliation provide an effective deterrent and combat force well into the 21 st century.

The blending of low-observable technologies with high aerodynamic efficiency and large payload gives the B-2 important advantages over existing bombers. 
Its low-observability provides it greater freedom of action at high altitudes, thus increasing its range and a better field of view for the aircraft's sensors. Its unrefueled range is approximately 6,000 nautical miles $(9,600 \mathrm{~km})$.

The B-2's low observability is derived from a combination of reduced infrared, acoustic, electromagnetic, visual and radar signatures. These signatures make it difficult for the sophisticated defensive systems to detect, track and engage the B-2.

Many aspects of the low-observability process remain classified; however, the B-2's composite materials, special coatings and flying-wing design all contribute to its "stealthiness."

The B-2 has a crew of two pilots, an aircraft commander in the left seat and mission commander in the right, compared to the B-1B's crew of four and the B52 's crew of five.

The B-2 is intended to deliver gravity nuclear and conventional weapons, including precision-guided standoff weapons.

An interim, precision-guided bomb capability called Global Positioning System (GPS) Aided Targeting System/GPS Aided Munition (GATS/GAM) is being tested and evaluated.

Future configurations are planned for the B-2 to be capable of carrying and delivering the Joint Direct Attack Munition (JDAM) and Joint Air-to-Surface Standoff Missile.

\section{Results}

The Northrop Grumman (formerly Ryan Aeronautical) RQ-4 Global Hawk (known as Tier II+ during development) is an Unmanned Aerial Vehicle (UAV) used by the United States Air Force and Navy and the German Air Force as a surveillance aircraft.

The Northrop Grumman B-2 Spirit (also known as the Stealth Bomber) is an American strategic bomber, featuring low observable stealth technology designed for penetrating dense anti-aircraft defenses; it is able to deploy both conventional and nuclear weapons. The bomber has a crew of two and can drop up to eighty 500 lb (230 kg)-class JDAM GPS-guided bombs, or sixteen $2,400 \mathrm{lb}(1,100 \mathrm{~kg}) \mathrm{B} 83$ nuclear bombs.

The B-2 is the only aircraft that can carry large air-tosurface standoff weapons in a stealth configuration.

The BQM-74 Chukar is a series of aerial target drones produced by Northrop. The Chukar has gone through three major revisions, including the initial MQM-74A Chukar I, the MQM-74C Chukar II and the BQM-74C Chukar III. They are recoverable, remote controlled, subsonic aerial target, capable of speeds up to Mach 0.86 and altitudes from 30 to $40,000 \mathrm{ft}$ (10 to $12,000 \mathrm{~m}$ ).

Northrop Grumman Corporation (NYSE: NOC) is an American global aerospace and defense technology company formed by the 1994 purchase of Grumman by Northrop.
The company was the fourth-largest defense contractor in the world as of 2010 and the largest builder of naval vessels. Northrop Grumman employs over 75,000 people worldwide. Its 2010 annual revenue is reported at US\$34 billion.

Northrop Grumman ranks \#72 on the 2011 Fortune 500 list of America's largest corporations and ranks in the top ten military-friendly employers. It has its headquarters in Falls Church, Virginia. Separate sectors, such as Aerospace Systems, produce aircraft for the US and other nations. The B-2 Spirit strategic bomber, the E-8C Joint STARS surveillance aircraft, the RQ-4 Global Hawk and the T-38 Talon supersonic trainer, are used by the US Air Force.

The US Army uses Northrop Grumman's RQ-5 Hunter unmanned air vehicle, which has been in operational use for more than 10 years. The US Navy uses Northrop Grumman-built aerial vehicles such as the BQM-74 Chukar, RQ-4 Global Hawk based BAMS UAS, C-2 Greyhound, E-2 Hawkeye and the EA-6B Prowler.

Northrop Grumman provides major components and assemblies for different aircraft such as F/A-18 Hornet, F/A-18E/F Super Hornet and the EA-18G Growler. Many aircraft, such as the F-5, T-38 Talon and E-2 Hawkeye are used by other nations.

\section{Discussion}

The Northrop Grumman B-2 Spirit (also known as the Stealth Bomber) is an American strategic bomber, featuring low observable stealth technology designed for penetrating dense anti-aircraft defenses; it is able to deploy both conventional and nuclear weapons.

The bomber has a crew of two and can drop up to eighty $500 \mathrm{lb}$ (230 kg)-class JDAM GPS-guided bombs, or sixteen 2,400 lb (1,100 kg) B83 nuclear bombs (Fig. 7), (Petrescu and Petrescu, 2009; 2011; 2012; 2013a; $2013 b ; 2013 c)$.

The B-2 is the only aircraft that can carry large air-tosurface standoff weapons in a stealth configuration. Development originally started under the "Advanced Technology Bomber" (ATB) project during the Carter administration and its performance was one of the reasons for his cancellation of the B-1 Lancer.

ATB continued during the Reagan administration, but worries about delays in its introduction led to the reinstatement of the B-1 program as well.

Program costs rose throughout development.

Designed and manufactured by Northrop Grumman with assistance from Boeing, the cost of each aircraft averaged US\$737 million (in 1997 dollars).

Total procurement costs averaged $\$ 929$ million per aircraft, which includes spare parts, equipment, retrofitting and software support.

The total program cost including development, engineering and testing, averaged $\$ 2.1$ billion per aircraft in 1997. 
Because of its considerable capital and operational costs, the project was controversial in the U.S. Congress and among the Joint Chiefs of Staff.

The winding-down of the Cold War in the latter portion of the 1980s dramatically reduced the need for the aircraft, which was designed with the intention of penetrating Soviet airspace and attacking high-value targets.

During the late 1980s and 1990s, Congress slashed initial plans to purchase 132 bombers to 21 .

In 2008, a B-2 was destroyed in a crash shortly after takeoff and the crew ejected safely.

A total of 20 B-2s remains in service with the United States Air Force.

Though originally designed primarily as a nuclear bomber, the B-2 was first used in combat to drop conventional bombs on Serbia during the Kosovo War in 1998 and saw continued use during the wars in Iraq and Afghanistan.

B-2s were also used during the 2011 Libyan civil war.

\section{Conclusion}

The Northrop Grumman (formerly Ryan Aeronautical) RQ-4 Global Hawk (known as Tier II+ during development) is an Unmanned Aerial Vehicle (UAV) used by the United States Air Force and Navy and the German Air Force as a surveillance aircraft.

The Northrop Grumman B-2 Spirit (also known as the Stealth Bomber) is an American strategic bomber, featuring low observable stealth technology designed for penetrating dense anti-aircraft defenses; it is able to deploy both conventional and nuclear weapons.

The bomber has a crew of two and can drop up to eighty $500 \mathrm{lb}(230 \mathrm{~kg})$-class JDAM GPS-guided bombs, or sixteen $2,400 \mathrm{lb}(1,100 \mathrm{~kg}) \mathrm{B} 83$ nuclear bombs. The B-2 is the only aircraft that can carry large air-to-surface standoff weapons in a stealth configuration.

The BQM-74 Chukar is a series of aerial target drones produced by Northrop.

The Chukar has gone through three major revisions, including the initial MQM-74A Chukar I, the MQM-74C Chukar II and the BQM-74C Chukar III.

They are recoverable, remote controlled, subsonic aerial target, capable of speeds up to Mach 0.86 and altitudes from 30 to $40,000 \mathrm{ft}$ ( 10 to $12,000 \mathrm{~m}$ ). Northrop Grumman Corporation (NYSE: NOC) is an American global aerospace and defense technology company formed by the 1994 purchase of Grumman by Northrop.

\section{Acknowledgement}

We acknowledge and thank $\mathrm{Mr}$ Taher M. AbuLebdeh, Associate Prof at North Carolina A and T State Univesity, United States and Mr Muftah H. El-Naas PhD MCIC FICCE QAFCO Chair Professor in Chemical Process Engineering Gas Processing Center College of
Engineering Qatar University and Ms Shweta Agarwala, Senior Research Scientist at Singapore Center for 3D Printing Nanyang Technological University Singapore for their suggestions and comments. The Authors acknowledge Liquid Metals Technologies Inc, Ca USA that kindly supply the samples for the characterization and Dr Francesco Tatti (FEI Company Application Specialist SEM-SDB) for its contribut in the preparation of this paper experiments and analyses. The authors would like to appreciate the facilities and assistance provided by the Advanced Technology Dental Research Laboratory, Faculty of dentistry, King Abdul Aziz University. The authors would also appreciate the research technicians, Basim $\mathrm{Al}$ Turki and Fahad $\mathrm{Al}$ Othaibi for their cooperation (Aversa et al., 2016a; 2016b; 2016c; 2016d; 2016e; 2016f; 2016g; 2016h; 2016i; 2016j; 2016k; 2016l; 2016m; 2016n; 2016o; 2017a; 2017b; 2017c; 2017d; 2017e; Mirsayar et al., 2017).

\section{Author's Contributions}

All the authors contributed equally to prepare, develop and carry out this manuscript.

\section{Ethics}

This article is original and contains unpublished material. The corresponding author confirms that all of the other authors have read and approved the manuscript and no ethical issues involved.

\section{References}

Aversa, R., R.V.V. Petrescu, A. Apicella and F.I.T. Petrescu, 2017a. Nano-diamond hybrid materials for structural biomedical application. Am. J. Biochem. Biotechnol.

Aversa, R., R.V. Petrescu, B. Akash, R.B. Bucinell and J.M. Corchado et al., 2017b. Kinematics and forces to a new model forging manipulator. Am. J. Applied Sci., 14: 60-80.

Aversa, R., R.V. Petrescu, A. Apicella, I.T.F. Petrescu and J.K. Calautit et al., 2017c. Something about the $\mathrm{V}$ engines design. Am. J. Applied Sci., 14: 34-52.

Aversa, R., D. Parcesepe, R.V.V. Petrescu, F. Berto and G. Chen et al., 2017d. Process ability of bulk metallic glasses. Am. J. Applied Sci., 14: 294-301.

Aversa, R., R.V.V. Petrescu, B. Akash, R.B. Bucinell and J.M. Corchado et al., 2017e. Something about the balancing of thermal motors. Am. J. Eng. Applied Sci., 10: 200.217. DOI: 10.3844/ajeassp.2017.200.217

Aversa, R., F.I.T. Petrescu, R.V. Petrescu and A. Apicella, 2016a. Biomimetic FEA bone modeling for customized hybrid biological prostheses development. Am. J. Applied Sci., 13: 1060-1067. DOI: 10.3844 /ajassp.2016.1060.1067 
Aversa, R., D. Parcesepe, R.V. Petrescu, G. Chen and F.I.T. Petrescu et al., 2016b. Glassy amorphous metal injection molded induced morphological defects. Am. J. Applied Sci., 13: 1476-1482.

Aversa, R., R.V. Petrescu, F.I.T. Petrescu and A. Apicella, 2016c. Smart-factory: Optimization and process control of composite centrifuged pipes. Am. J. Applied Sci., 13: 1330-1341.

Aversa, R., F. Tamburrino, R.V. Petrescu, F.I.T. Petrescu and M. Artur et al., 2016d. Biomechanically inspired shape memory effect machines driven by muscle like acting NiTi alloys. Am. J. Applied Sci., 13: 1264-1271.

Aversa, R., E.M. Buzea, R.V. Petrescu, A. Apicella and M. Neacsa et al., 2016e. Present a mechatronic system having able to determine the concentration of carotenoids. Am. J. Eng. Applied Sci., 9: 1106-1111.

Aversa, R., R.V. Petrescu, R. Sorrentino, F.I.T. Petrescu and A. Apicella, 2016f. Hybrid ceramo-polymeric nanocomposite for biomimetic scaffolds design and preparation. Am. J. Eng. Applied Sci., 9: 1096-1105.

Aversa, R., V. Perrotta, R.V. Petrescu, C. Misiano and F.I.T. Petrescu et al., 2016g. From structural colors to super-hydrophobicity and achromatic transparent protective coatings: Ion plating plasma assisted $\mathrm{TiO}_{2}$ and $\mathrm{SiO}_{2}$ Nano-film deposition. Am. J. Eng. Applied Sci., 9: 1037-1045.

Aversa, R., R.V. Petrescu, F.I.T. Petrescu and A. Apicella, 2016h. Biomimetic and evolutionary design driven innovation in sustainable products development. Am. J. Eng. Applied Sci., 9: 1027-1036.

Aversa, R., R.V. Petrescu, A. Apicella and F.I.T. Petrescu, 2016i. Mitochondria are naturally micro robots-a review. Am. J. Eng. Applied Sci., 9: 991-1002.

Aversa, R., R.V. Petrescu, A. Apicella and F.I.T. Petrescu, 2016j. We are addicted to vitamins $\mathrm{C}$ and E-A review. Am. J. Eng. Applied Sci., 9: 1003-1018.
Aversa, R., R.V. Petrescu, A. Apicella and F.I.T. Petrescu, 2016k. Physiologic human fluids and swelling behavior of hydrophilic biocompatible hybrid ceramo-polymeric materials. Am. J. Eng. Applied Sci., 9: 962-972.

Aversa, R., R.V. Petrescu, A. Apicella and F.I.T. Petrescu, 20161. One can slow down the aging through antioxidants. Am. J. Eng. Applied Sci., 9: 1112-1126.

Aversa, R., R.V. Petrescu, A. Apicella and F.I.T. Petrescu, 2016m. About homeopathy or «Similia similibus curentur $\gg$. Am. J. Eng. Applied Sci., 9: 1164-1172.

Aversa, R., R.V. Petrescu, A. Apicella and F.I.T. Petrescu, 2016n. The basic elements of life's. Am. J. Eng. Applied Sci., 9: 1189-1197.

Aversa, R., F.I.T. Petrescu, R.V. Petrescu and A. Apicella, 2016o. Flexible stem trabecular prostheses. Am. J. Eng. Applied Sci., 9: 1213-1221.

Mirsayar, M.M., V.A. Joneidi, R.V.V. Petrescu, F.I.T. Petrescu and F. Berto, 2017 Extended MTSN criterion for fracture analysis of soda lime glass. Eng. Fracture Mechanics 178: 50-59.

DOI: 10.1016/j.engfracmech.2017.04.018

Petrescu, R.V. and F.I. Petrescu, 2013a. Lockheed Martin. 1st Edn., CreateSpace, pp: 114.

Petrescu, R.V. and F.I. Petrescu, 2013b. Northrop. 1st Edn., CreateSpace, pp: 96.

Petrescu, R.V. and F.I. Petrescu, 2013c. The Aviation History or New Aircraft I Color. 1st Edn., CreateSpace, pp: 292.

Petrescu, RV., Petrescu, FIT., 2012a Northrop. 1st Edn., Books on Demand, ISBN-13: 978- 3848209323, pp: 142.

Petrescu, F.I. and R.V. Petrescu, 2012b. New Aircraft II. 1st Edn., Books on Demand, pp: 138.

Petrescu, F.I. and R.V. Petrescu, 2011. Memories About Flight. 1st Edn., CreateSpace, pp: 652.

Petrescu, F.I.T., 2009. New aircraft. Proceedings of the 3rd International Conference on Computational Mechanics, Oct. 29-30, Brasov, Romania. 